\title{
IMMUNE REGULATION BY HELMINTH PARASITES: CELLULAR AND MOLECULAR MECHANISMS
}

Rick M. Maizels ${ }^{\star}$ and Maria Yazdanbakhsh

Immunology was founded by studying the body's response to infectious microorganisms, and yet microbial prokaryotes only tell half the story of the immune system. Eukaryotic pathogens protozoa, helminths, fungi and ectoparasites - have all been powerful selective forces for immune evolution. Often, as with lethal protozoal parasites, the focus has been on acute infections and the inflammatory responses they evoke. Long-lived parasites such as the helminths, however, are more remarkable for their ability to downregulate host immunity, protecting themselves from elimination and minimizing severe pathology in the host.

T HELPER 1/T HELPER 2 CELL $\left(\mathrm{T}_{\mathrm{H}} 1 / \mathrm{T}_{\mathrm{H}} 2\right)$. A classification of $\mathrm{CD} 4^{+} \mathrm{T}$ cells on the basis of the patterns of cytokines that they secrete. $T_{H} 1$ cells secrete large amounts of interferon- $\gamma$ and associated pro-inflammatory cytokines. $\mathrm{T}_{\mathrm{H}} 2$ cells secrete large amounts of interleukin- 4 and associated cytokines that promote antibody production by $B$ cells. $T_{H} 1 / T_{H} 2$ cytokines can cross-regulate each other's responses. An imbalance of $\mathrm{T}_{\mathrm{H}} 1 / \mathrm{T}_{\mathrm{H}} 2$-cell responses is thought to contribute to the pathogenesis of various infections, allergic responses and autoimmune diseases.

${ }^{*}$ Institute for Cell, Animal and Population Biology, University of Edinburgh, West Mains Road, Edinburgh EH9 3JT, UK. ${ }^{\ddagger}$ Leiden University Medical Centre, Leiden 2300RC, The Netherlands. Correspondence to R. M. M. e-mail:r.maizels@ed.ac.uk doi:10.1038/nri1183
Helminths are complex eukaryotic organisms with large genomes, endowing some species with the ability to live for decades in the human host ${ }^{1}$. Parasitic helminths infect more than two billion people in the world today, and cause marked morbidity and disability. In many infected individuals, parasitism leads to severe immunopathological complications such as granulomatous disease and organ failure. However, it is more common for the host-parasite interplay to seem harmonious, and clinically asymptomatic carriers act as long-term reservoirs for transmission (BOX 1). Although these infections might seem clinically to go unnoticed by the immune system, it is unlikely that the host remains ignorant of the parasite. Rather, highly effective mechanisms of immune subversion are clearly at play. In this review, we focus on new insights into immune regulation by helminths, and the growing number of new immunomodulatory molecules that are produced by parasites to exert their marked downregulatory effects.

\section{Immunomodulation by helminths}

The immunomodulatory effects of helminths are marked (FIG. 1). Both parasite-antigen-specific and more generalized levels of immune suppression are well documented in human studies. For example, patients with tissue helminth infections, such as schistosomiasis and filariasis, have diminished responsiveness to antigens from the infecting parasite ${ }^{2-4}$. More broadly, helminth infections are associated with downmodulated responsiveness in general, in some cases with measurable attenuation of responses to bystander antigens ${ }^{5}$, routine vaccinations $s^{6,7}$ or allogeneic tissue transplants ${ }^{8}$. Such 'spillover suppression' is related to the intensity of infection $^{9}$, and extends to polyclonal responses to mitogens. Helminth infection can even have beneficial outcomes in reducing inflammatory disease caused by infection with Helicobacter pylori ${ }^{10}$ and Plasmodium falciparum ${ }^{11}$.

A similar interplay between helminth-mediated downmodulation of the immune system and potential immune-mediated pathologies is now emerging with respect to diminished allergic manifestations in individuals with helminth infections. Schistosome-infected children have been shown to have lower levels of skin reactivity to allergens than uninfected classmates, indicating that the immune system might be influenced by the presence of parasites $^{12}$. These findings have led to a major shift in the hygiene hypothesis, the founding tenet of which was that T HELPER $2\left(\mathrm{~T}_{\mathrm{H}} 2\right)$-CELL mediated allergies would be counteracted by microorganisms that induce $\mathrm{T}_{\mathrm{H}} 1$ cells. Because $\mathrm{T}_{\mathrm{H}}$ 2-inducing helminths (see later) are associated with the inhibition of $\mathrm{T}_{\mathrm{H}} 2$ mediated inflammatory disease, mechanisms involving non- $\mathrm{T}_{\mathrm{H}} 1$-cell populations, such as regulatory $\mathrm{T}\left(\mathrm{T}_{\mathrm{Reg}}\right)$ cells, are now being considered ${ }^{13,14}$. 
Marked polarization towards $T_{H} 2$ cells. Helminths are the main examples of $\mathrm{T}_{\mathrm{H}} 2$-cell inducers in both humans and experimental models: high-level tissue eosinophilia, mucosal mastocytosis and, above all, the production of immunoglobulin $\mathrm{E}$ are observed ${ }^{15-18}$. Generally, infectious-stage organisms induce the production of immediate type- 2 cytokine responses, from both $\mathrm{CD}^{+}{ }^{+} \mathrm{T}$ cells and other sources, within 24 hours of entry into the host ${ }^{19}$. The drive towards $\mathrm{T}_{\mathrm{H}} 2$-cell polarization is so potent in many helminth infections that bystander proteins become targets for $\mathrm{T}_{\mathrm{H}} 2$-cell responses, including IgE antibodies ${ }^{20,21}$, and naive $\mathrm{T}$ cells that express receptors for unrelated antigens differentiate to the $\mathrm{T}_{\mathrm{H}}$ 2-cell phenotype $\mathrm{e}^{22}$.

There are several interesting exceptions to the canonical rule of $\mathrm{T}_{\mathrm{H}} 2$-cell skewing by helminths. First, the initial infective stages of schistosomes (cercariae) stimulate $\mathrm{T}_{\mathrm{H}} 1$-cell responses in the mouse model. Only as infection progresses and eggs are released by fecund adults in the vasculature does the response switch to a $\mathrm{T}_{\mathrm{H}} 2$-cell response, driven by the schistosome-egg antigens ${ }^{18}$. Second, the newborn microfilarial stage of Brugia malayi promotes $\mathrm{T}_{\mathrm{H}} 1$-cell responses in mice, although adult female worms, which release microfilariae in vivo, promote $\mathrm{T}_{\mathrm{H}} 2$-cell differentiation ${ }^{23}$. Third, the gut nematode Trichuris muris (FIG. 2 ) induces $\mathrm{T}_{\mathrm{H}} 1$ - or $\mathrm{T}_{\mathrm{H}} 2$-cell responses in mice of different strains ${ }^{24}$. These will be fascinating subjects to study in terms of not only T-cell phenotype induction, but also maintaining subset dominance.

Additional crucial issues have yet to be resolved. What mediators or ligands from helminth parasites stimulate the immediate $\mathrm{T}_{\mathrm{H}} 2$-cell response? Which host-cell receptors and subpopulations are involved in generating and maintaining the $\mathrm{T}_{\mathrm{H}} 2$-cell phenotype? And, does the parasite or host benefit from the sustained $\mathrm{T}_{\mathrm{H}} 2$-cell bias that accompanies chronic infection with helminths?

$T_{H}$ 2-cell inflammation - a case for regulation? A common over-generalization is that $\mathrm{T}_{\mathrm{H}} 2$-cell responses protect against helminth infection. Although human studies on schistosomiasis ${ }^{25}$ and other helminths often have associated $\mathrm{T}_{\mathrm{H}} 2$-cell responses with protection from re-infection, there is also evidence that naturally immune individuals that are resistant to infection have

\section{Box 1 | Immunology of human infections with Schistosoma mansoni and Brugia malayi}

The exposure to these parasites can result in three broad outcomes that are associated with specific immune responses. One group of individuals are susceptible to infection and have immunological responses described as ' $m$ modified $\mathrm{T}$ helper 2 ( $\mathrm{T}_{\mathrm{H}}$ 2)-cell responses. They have $\mathrm{T}_{\mathrm{H}}$ 2-cell responses, with low levels of $\mathrm{T}_{\mathrm{H}} 1$ cells, and express high levels of interleukin-10 (IL-10), which might indicate a strong regulatory $\mathrm{T}\left(\mathrm{T}_{\mathrm{Beg}}\right)$-cell activity. The $\mathrm{T}_{\mathrm{H}}$-type antibody profiles are dominated by the IgG4 isotype with relatively little IgE. These individuals often have clinically silent infections and are the main reservoir for onward transmission. At the other extreme, some individuals develop uncontrolled inflammatory $\left(T_{H} 1\right)$ disease. In schistosomiasis, strong immune responses can be mounted against eggs that are trapped in tissues, such as the liver or the bladder wall, leading to the formation of granulomas. Uncontrolled inflammatory responses, often characterized by type-1 responses in peripheral blood, are associated with hepatosplenic disease. There are only low levels of IgG4 but IgE responses are evident. In filariasis, strong type-1 immune responses are associated with lymphatic inflammation. This leads to pathological outcomes, such as elephantiasis, which is caused by the failure of lymphatic drainage and opportunistic secondary infection. In such cases, it would be expected that a low activity of regulatory $\mathrm{T}$ cells occured. A third group of individuals seem to be resistant to infections. In this group, well-balanced immune responses would be characterized by the presence of measured $\mathrm{T}_{\mathrm{H}} 1$ - and $\mathrm{T}_{\mathrm{H}} 2$-cell responses that are controlled due to the presence of $\mathrm{T}_{\mathrm{Re}}$-cell activity. It is envisaged that the balanced $\mathrm{T}_{\mathrm{H}} 1$ - and $\mathrm{T}_{\mathrm{H}}$ 2-cell responses are of sufficient magnitude to kill the invading helminths. This is also reflected in a less skewed distribution of IgG4 and IgE isotypes in the $\mathrm{T}_{\mathrm{H}} 2$-type antibody profile.

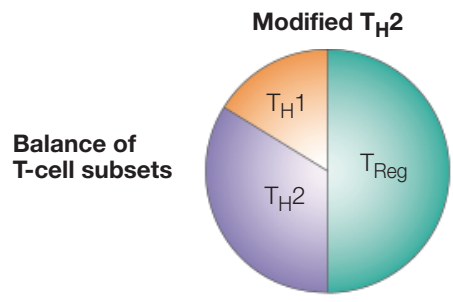

Antibody response

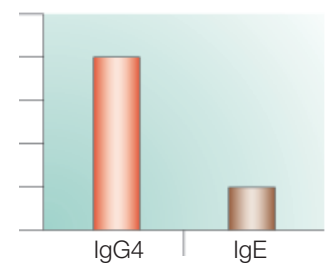

Susceptible individuals with long-lived metabolically active adult worms in peripheral tissues
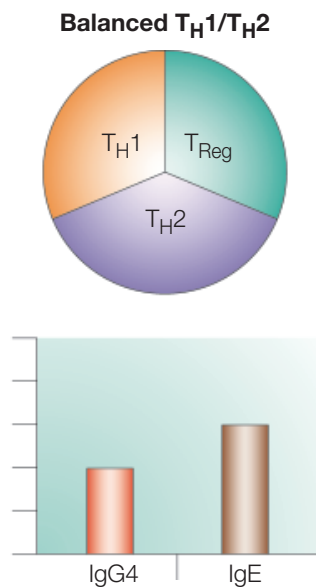

Resistant individuals remaining free of infection
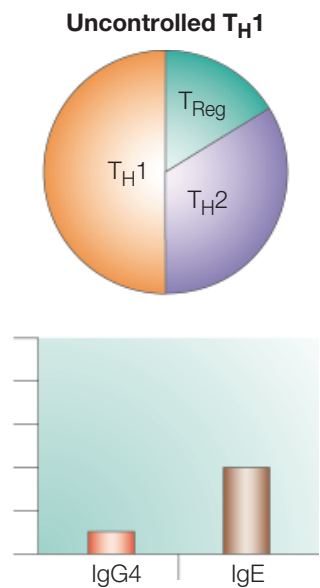

Individuals with clinical disease 


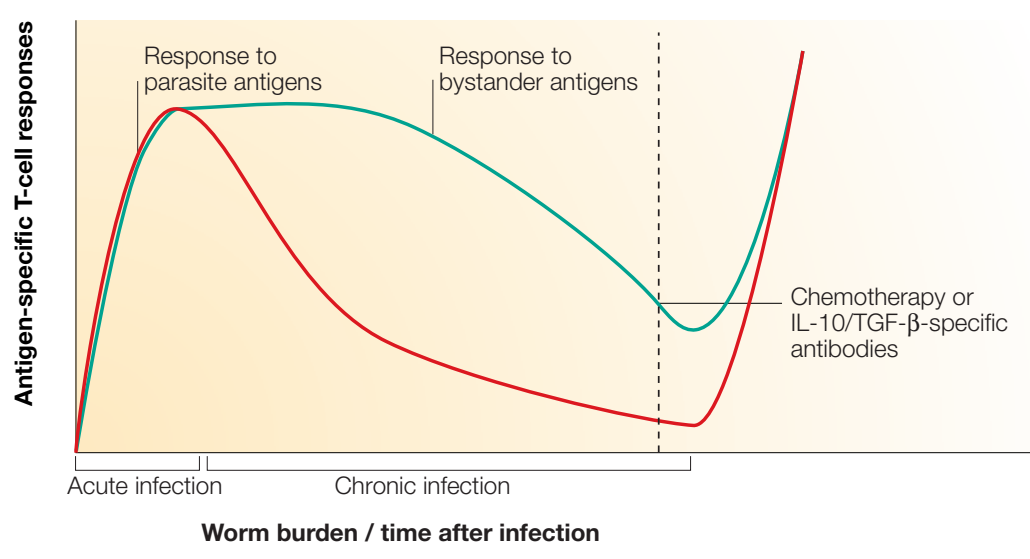

Figure 1 | System-wide effects of helminth immunomodulation. A generic time course is postulated for the establishment of regulation over the course of an infection. During acute infection, antigen-specific T-cell responses are initially stimulated and cells proliferate in response to parasite antigens. With increasing exposure of the immune system to parasite antigens that are released from metabolically active worms, the immune system becomes increasingly hyporesponsive, first to specific parasite antigens and subsequently, when high worm burdens occur, to bystander antigens. Curative chemotherapy restores antigen-specific responses. The treatment of T-cell cultures with antibodies specific for interleukin-10 (IL-10) or transforming growth factor- $\beta$ (TGF- $\beta$ ) can also rescue antigen-specific proliferation. The increased production of IL-10 and TGF- $\beta$ that is responsible for inhibiting T-cell proliferation might be released either from antigen-presenting cells or T cells, and is postulated to be the result of downmodulatory molecules that are released from the worms to enhance their survival.

$\mathrm{T}_{\mathrm{H}} 1$-cell-dominated responses ${ }^{26}$. A similar ambiguity exists in animal models, in which a clear protective role for the $\mathrm{T}_{\mathrm{H}} 2$-cell arm of immunity has been shown only for gastrointestinal nematode infections in mice ${ }^{24,27,28}$ (FIG. 2). In the gut environment, type 2 cytokines, including interleukin-3 (IL-3), IL-4, IL-9 and IL-13 act on mast cells, non-lymphoid epithelial cells and goblet cells to induce the expulsion of parasites through physiological reactions, such as mucus production and muscle hypercontractivity ${ }^{29,30}$. Each parasite species is susceptible to different pathways of expulsion. So, mucosal mast cells underpin resistance to T. muris ${ }^{31}$ and goblet cells mediate resistance to Nippostrongylus brasiliensis ${ }^{28}$, with both cell types dependent on the IL-4 receptor-STAT6 (signal transducer and activator of transcription 6) pathway for their activation ${ }^{32}$.

Many helminth parasites migrate through epithelial tissues, muscle and the lungs and here, few protective mechanisms depend on type-2-mediated effects ${ }^{33}$. Exceptions do occur: for example, IL-5-overexpressing mice have large numbers of eosinophils and rapidly kill the larvae of N. brasiliensis ${ }^{34}$ and Strongyloides stercoralis $^{35}$. However, eosinophils, in general, do not have a role in the expulsion of adult worms ${ }^{36}$. So, distinct mechanisms are invoked not only to eliminate different species of helminth, but also to kill different life-cycle stages of the same species. Vaccination of mice can elicit protective responses to challenge with Schistosoma mansoni, and these are equally effective whether they are dominated by $\mathrm{T}_{\mathrm{H}} 1$ - or $\mathrm{T}_{\mathrm{H}} 2$-cell responses ${ }^{37}$. The strongest protective effect is observed in IL-10-deficient mice, in which both $\mathrm{T}_{\mathrm{H}} 1$ - and $\mathrm{T}_{\mathrm{H}}$ 2-cell responses develop to the highest level ${ }^{38}$.
The argument has perhaps dwelled too long on an assumed pivotal balance between $\mathrm{T}_{\mathrm{H}} 1$ - and $\mathrm{T}_{\mathrm{H}}$ 2-cell responses ${ }^{39}$. Several considerations now require a more sophisticated model. First, individual cytokines can have crucial effects in both type- 1 and type- 2 responses. For example, although tumour-necrosis factor (TNF) is regarded as a type- 1 cytokine, it is required at an early stage in infection to synergize with the $\mathrm{T}_{\mathrm{H}}$-effector mechanism that expels the gut worm T. muris ${ }^{40}$, and it also acts downstream of IL-4 to cause gut enteropathy in the $\mathrm{T}_{\mathrm{H}}$ 2-type environment ${ }^{41}$. Second, although a combination of $\mathrm{T}_{\mathrm{H}} 1$ - and $\mathrm{T}_{\mathrm{H}} 2$-cell responses is required for healthy resolution of infection ${ }^{42}$, an exaggerated response of either type is damaging to the host ${ }^{43,44}$. And third, T-cell subsets can be further subdivided not only into variants of $\mathrm{T}_{\mathrm{H}} 1$ and $\mathrm{T}_{\mathrm{H}} 2$ cells, but also more broadly into $\mathrm{T}_{\text {Reg }}$ cells that can dampen both $\mathrm{T}_{\mathrm{H}} 1$ - and $\mathrm{T}_{\mathrm{H}}$ 2-cell activation ${ }^{45,46}$.

However, although the $\mathrm{T}_{\mathrm{H}}$ 2-cell response might have limited effects on parasite burden, it exerts an enormous influence on the survival of the host. $\mathrm{T}_{\mathrm{H}} 2$ cytokines modulate excessive inflammatory reactions, preventing a runaway pathology ${ }^{44}$. After 8 weeks of S. mansoni infection, wild-type (C57BL/6) mice enter a chronic phase of eggs accumulating in the liver, whereas IL-4-deficient mice die of inflammatory reactions to parasites ${ }^{47}$. By autopsy, both groups were shown to have similar numbers of adult worms and eggs, but the IL-4-deficient animals had uncontrolled TNF production to which their demise is attributed. In this context, the $\mathrm{T}_{\mathrm{H}} 2$-cell response protects the host not from infection per se, but from the potential pathogenic damage caused by unrestricted $\mathrm{T}_{\mathrm{H}} 1$-cell-mediated inflammation ${ }^{18,48}$. However, there are also circumstances in which the $\mathrm{T}_{\mathrm{H}} 2$-cell response itself causes pathology, as in the severe IL-4dependent villous atrophy and crypt hyperplasia that accompanies T. muris infection ${ }^{41}$. Most markedly, the formation of granulomas in schistosomiasis, which triggers a lethal cascade in IL-4-deficient mice, is mediated by IL-13 (REFS 49,50) and can be blocked with soluble IL-13 receptor. So, the $\mathrm{T}_{\mathrm{H}} 2$-cell response itself has both pro- and anti-inflammatory functions in helminth infections, as is known for other important pathologies, such as asthma and autoimmunity.

When the host immune response is of the $\mathrm{T}_{\mathrm{H}} 2$ type, the host must also ensure that only a regulated response is generated. Maintaining a limit on $\mathrm{T}_{\mathrm{H}}$ 2-cell reactivity might be achieved through a homeostatic mechanism (the modified $\mathrm{T}_{\mathrm{H}}$ 2-cell response) or by a more directed evolution of $\mathrm{T}_{\text {Reg }}$ cells. We suggest that if either of these mechanisms is deficient, pathology might be the result.

\section{The modified $\mathbf{T}_{\mathrm{H}}$ 2-cell response}

A restrained form of the $\mathrm{T}_{\mathrm{H}}$ 2-cell response can be envisaged with a less aggressive action. Such a phenotype has been classified as a 'modified $\mathrm{T}_{\mathrm{H}} 2$-cell response' in individuals who do not develop allergic disease despite high levels of exposure to allergen ${ }^{51}$. The main feature of the modified $\mathrm{T}_{\mathrm{H}}$ 2-cell response is the uncoupling of specific IgG4 and IgE responses, with downregulation of the latter isotype. Both IgG4 and IgE class switching are 


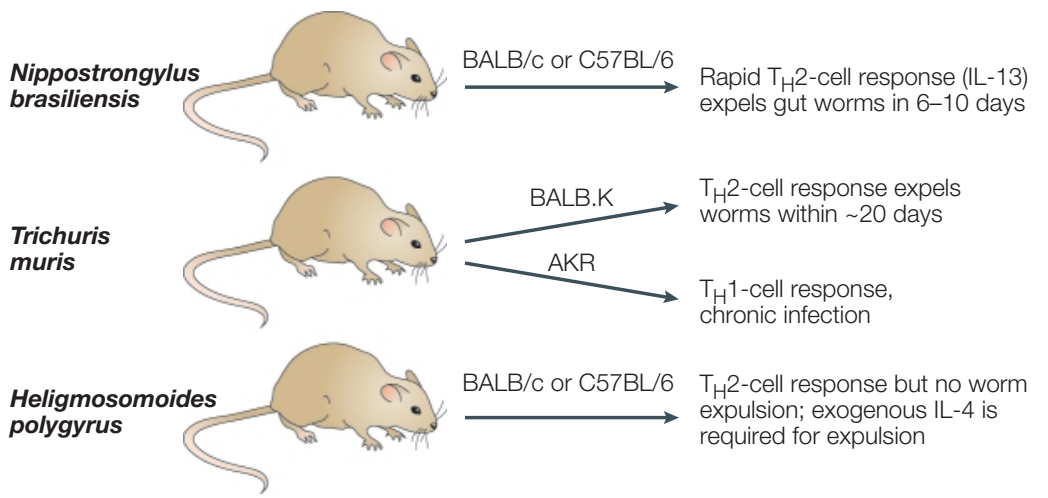

Figure 2 | Rodent models of infection with intestinal nematodes. For each of the three helminth species, different patterns of susceptibility are found, depending on the mouse strain and on the particular cytokines and T-cell responses that are induced. IL, interleukin; $T_{H}$, T helper.

known to be promoted by IL-4. However, it has been shown that IL-10 inhibits B-cell switching to IgE, while inducing the production of IgG4 by the same cells ${ }^{52}$. IL-10 is a downmodulatory factor in allergic disease, and might be produced by the modified $\mathrm{T}_{\mathrm{H}} 2$ cells themselves or by other populations, such as antigenpresenting cells (APCs), that function to induce the modified $\mathrm{T}_{\mathrm{H}}$ 2-cell phenotype.

The literature on helminth infections provides many examples that are consistent with $\mathrm{T}_{\mathrm{H}}$ 2-cell modification. In human cases of filariasis pathology (such as elephantiasis), parasite-specific responses comprise both IgE and IgG4 antibodies. By contrast, the more common asymptomatic, but highly infected microfilaraemic carriers have high levels of specific IgG4, but lower levels of $\mathrm{IgE}^{53}$. So, in both allergy and helminth infection, high antigen loads are associated with the modified $\mathrm{T}_{\mathrm{H}}$ 2-cell phenotype. A further modification of the $\mathrm{T}_{\mathrm{H}} 2$ type involves downregulated IL-5 responses to antigen, which would reduce the involvement of eosinophils in type-2-mediated inflammation ${ }^{4,54,55}$.

In most other helminth infections, evidence of modulated $\mathrm{T}_{\mathrm{H}} 2$-cell responses can also be found. For example, studies of granuloma formation in mouse schistosomiasis show a regression in the intensity and size in later infection, a downmodulatory process that can be transferred by $\mathrm{T}$ cells to a more-recently infected animal $^{56}$. In the schistosome-infected liver, expression of the decoy receptor IL-13R $\alpha 2$ is induced, which blocks IL-13-dependent fibrotic reactions ${ }^{57}$. As IL-13 itself is an inducer of IL-13R $\alpha 2$, a feedback loop seems to act entirely within the $\mathrm{T}_{\mathrm{H}} 2$-cell response to limit potential damage. Although the IL-13 regulatory circuit has not been linked directly to later downmodulation of granuloma size, it is a good example of modification and, possibly, maturation of the $\mathrm{T}_{\mathrm{H}} 2$-cell response.

Can modified $\mathrm{T}_{\mathrm{H}}$ 2-cell responses alter the outcome of infection in rodent model systems? Some apparent paradoxes indicate so. For example, a strong $\mathrm{T}_{\mathrm{H}} 2$-cell response occurs in all strains of mice that are infected with Heligmosomoides polygyrus (FIG. 2). Many strains, however, fail to expel the parasite, indicating either that the $\mathrm{T}_{\mathrm{H}}$ 2-cell response is adopting a modified form, or that another mode of the immune system (such as $\mathrm{T}_{\text {Reg }}$ cells) is intervening to prevent expulsion. A similar situation occurs during infection with the tissue filarial nematode Litomosoides sigmodontis, in which C57BL/6 mice mount an IL-4-dependent protective $\mathrm{T}_{\mathrm{H}}$ 2-cell response, yet the $\mathrm{T}_{\mathrm{H}}$ 2-cell response of $\mathrm{BALB} / \mathrm{C}$ mice cannot kill the parasites ${ }^{58}$.

\section{Regulatory T cells}

Longitudinal analyses in experimental infections, as well as immunoepidemiological studies in human populations, point to a scenario in which early immune reactivity undergoes gradual attrition in terms of parameters such as T-cell proliferation and inflammatory-cytokine production $^{55,59}$ (FIG. 1). Most strongly associated with this loss of responsiveness, both antigen-specific and polyclonal, are the cytokines IL-10 and transforming growth factor- $\beta$ (TGF- $\beta$ ), indicating that regulatory populations are activated during infection. In S. mansoni infection of mice, for example, initial $\mathrm{T}_{\mathrm{H}} 0 / \mathrm{T}_{\mathrm{H}} 1$-cell responses give way first to pro-inflammatory $\mathrm{T}_{\mathrm{H}} 2$-cell responses, followed by a decline in parasite-specific $\mathrm{T}$-cell responses in a more regulated environment.

The prominence of IL-10 as a crucial mediator of regulation in parasite infections has long been recognized $^{60}$, particularly for its role in attenuating pathogenesis. Studies with IL-10-deficient mice show a failure to control pathological reactions, with fatal results in infections with T. muris ${ }^{61}$, and increased mortality in infections with S. mansoni ${ }^{62}$. In one study, IL-10deficient animals fail to enter the late downmodulating phase in which the size of liver granulomas decreases ${ }^{63}$.

In human filariasis, heavily infected individuals have constitutively high IL-10 levels ${ }^{64}$ and IL-10 messenger RNA production, which is inversely correlated with T-cell proliferation. Filarial-specific T-cell proliferation can be restored in vitro by antibodies specific for IL-10 and/or TGF- $\beta^{2,65}$. In onchocerciasis ${ }^{5,66}$ and schistosomiasis, similar reversals are observed ${ }^{67,68}$. Similarly, IL-10-specific antibody rescues interferon- $\gamma($ IFN- $\gamma$ ) responses to schistosome antigen $s^{68,69}$. These studies did not, however, address whether the IL-10 response is antigen specific.

Do $\mathrm{T}_{\mathrm{Reg}}$ cells participate in the host response to helminths? Preliminary evidence to support this idea is now emerging. In onchocerciasis, parasite-antigenspecific T-cell clones that secrete IL-10 and TGF- $\beta$, but not IL-2, were isolated from a patient whose peripheral $\mathrm{T}$ cells were hyporesponsive ${ }^{66}$. Similar T-cell clones could also be recovered from the onchocercoma - the capsule around the local site of Onchocerca adult worms - which were cytotoxic T lymphocyte antigen 4 (CTLA4) positive and functioned to inhibit the proliferation of bystander $\mathrm{T}$ cells $\mathrm{s}^{70}$. Flow cytometric analysis of peripheral $\mathrm{T}$ cells in lymphatic filariasis has indicated the expansion of CTLA4 ${ }^{+} \mathrm{T}$-cell populations in individuals with suppressed T-cell function, and showed that CTLA4-specific antibodies increased the production of IL- 5 by T cells in response to antigen in vitro ${ }^{71}$. In our own work on mouse filariasis, high numbers of CTLA $4^{+} \mathrm{CD} 4^{+} \mathrm{T}$ cells, also expressing the 
$\mathrm{T}_{\text {Reg }}$-cell-associated marker GITR (glucocorticoidinduced TNF receptor-related protein $)^{45}$, accumulate around the site of infection, whereas neutralization of $\mathrm{T}_{\text {Reg }}$ cells with GITR-specific or CD25-specific antibodies renders mice more resistant to infection with L. sigmodontis (M. Taylor, L. Le Goff, E. Malone, A. Harris, J. E. Allen and R. M. M., unpublished observations).

The general concept for $\mathrm{T}_{\text {Reg }}$ cells has been that they are autoreactive thymic emigrants, otherwise known as 'natural' $\mathrm{T}_{\mathrm{Reg}}$ cells ${ }^{72}$. However, the need to control responses to external antigens such as commensal flora ${ }^{73}$ begs the question of whether naive $\mathrm{T}$ cells can selectively mature into $\mathrm{T}_{\text {Reg }}$ cells in the periphery. The existence of $\mathrm{T}_{\text {Reg }}$ cells that recognize bacterial ${ }^{74,75}$ and protozoal ${ }^{76}$ antigens underscores this question. Can helminths activate pre-existing (natural) $\mathrm{T}_{\text {Reg }}$ cells, as indicated by evidence of a role for $\mathrm{T}_{\mathrm{Reg}}$ cells immediately after infection? Parasites could also convert naive T cells into either antigen-specific or antigen non-specific $\mathrm{T}_{\mathrm{Reg}}$ cells through unknown pathways. With increasing knowledge of the molecular products of helminths (as described later), and advances in the characterization of $\mathrm{T}_{\mathrm{Reg}}$ cells, these questions will be answered in the near future.

Regulatory accessory cells? Antigen-presenting dendritic cells (DCs) make the first encounter with a parasite, reacting either to specific or generic signals to polarize T-cell responses ${ }^{77}$. Arguably more important in the context of chronic helminth infection is that accessory-cell populations can mediate modulatory functions on a

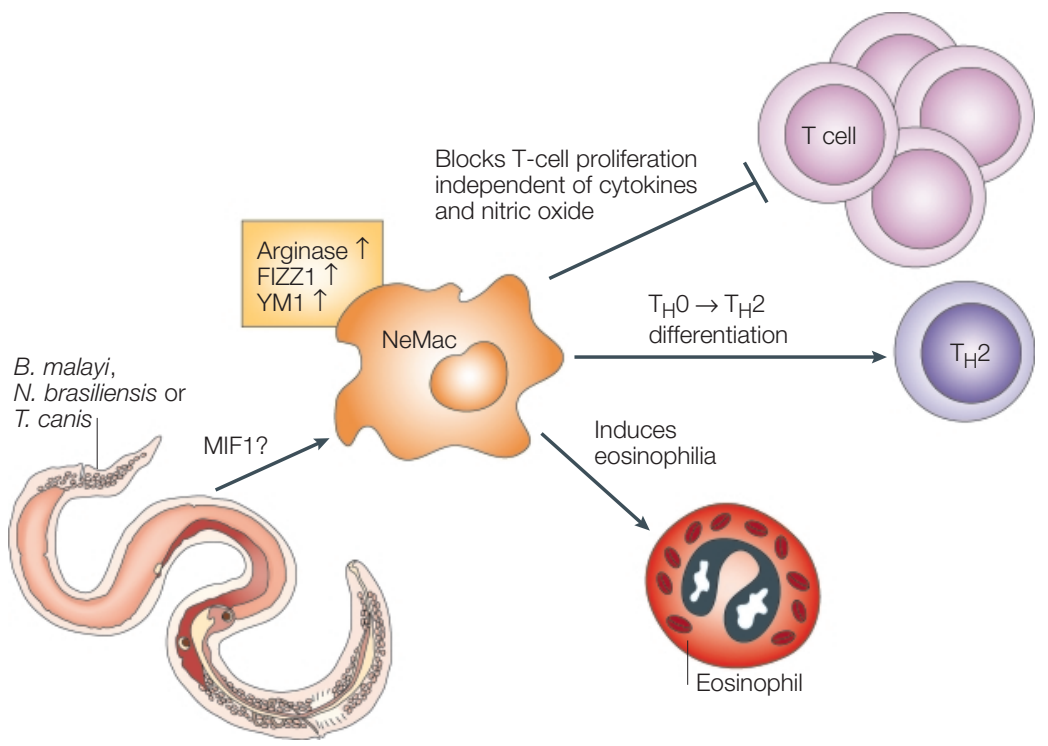

Figure $3 \mid$ Alternatively activated macrophages. Helminth infections in the peritoneal cavity for example with Brugia malayi, Nippostrongylus brasiliensis and Toxocara canis - elicit a new phenotype of macrophage, nematode-elicited macrophages (NeMacs), which are similar to alternatively activated or type-2 macrophages ${ }^{82,86}$. Among their features are: marked suppression of target cell proliferation through a contact-dependent mechanism that does not require interleukin-4 (IL-4), IL-10, prostaglandins or nitric oxide; induction of Thelper $2\left(T_{H} 2\right)$-cell differentiation of naive T-cell receptor-transgenic T cells; attraction of eosinophils; and a unique profile of gene expression that includes arginase and two new genes, YM1 and FIZZ1. One recombinant protein from B. malayi, the cytokine mimic macrophage-migration inhibition factor 1 (Bm-MIF1), induces the expression of YM1, as well as eosinophilia. This effect is lost in a Bm-MIF1 mutant in which a single amino acid has been altered (proline to glycine) ${ }^{122}$. So, $B m-M I F 1$ might be a necessary, but not sufficient, stimulus for macrophages to adopt the alternatively activated phenotype. steady-state basis. Suppressive adherent cells were identified 20 years ago in long-term infected humans ${ }^{78}$ and animals ${ }^{79}$, and subsequent studies have shown that the production of IL-10 by macrophages is one pathway by which this suppression can take place ${ }^{80-82}$. Although accessory cells, such as macrophages, express no antigen-specific receptors, their modulatory effects can often be imposed on the antigen-specific response by co-localization in a microenvironment that is occupied by responding lymphocytes.

An important advance has been the discovery of a new form of macrophage that arises in nematode infections, which operates through an IL-10-independent pathway $^{82,83}$ as summarized in FIG. 3. First found in the peritoneum of mice infected with B. malayi, similar cells occur in animals that are exposed to other nematodes and their secreted products ${ }^{84}$. Nematode-elicited macrophages (NeMacs) are larger and more multivacuolar in morphology than other macrophages, and have a markedly different profile of gene expression. In place of inflammatory nitric-oxide production, these cells upregulate the expression of arginase (which competes for the substrate of nitric-oxide synthase) and two new proteins YM1 and FIZZ1 (REFS 85,86). Because YM1 has also been identified as eosinophil chemotactic factor, this might explain why the recruitment of NeMacs is accompanied by a localized infiltration of eosinophils. These macrophages are markedly cytostatic, preventing the proliferation of non-lymphoid cells, as well as $\mathrm{T}$ cells, and they act through a contact-dependent mechanism that is independent of known inhibitors such as nitric oxide, prostaglandins or the cytokines IL-10 and TGF- $\beta^{87}$. Moreover, NeMacs induce the differentiation of naive mouse $\mathrm{T}$ cells into $\mathrm{T}_{\mathrm{H}} 2$ cells ${ }^{88}$ and can perhaps be considered as type- 2 macrophages. Overall, the suppressive NeMacs are an important in vivo example of alternatively activated macrophages ${ }^{89}$.

In their first encounter with DCs, helminths seem to take a more stealthy approach. Mouse bone-marrowderived DCs stimulated by helminths show limited upregulation of CD80, CD86 and MHC class II expression in comparison to expression induced by bacterial stimulant ${ }^{90,91}$. Data from experiments using microarray technology indicate that few of the lipopolysaccharide (LPS)-inducible genes are switched on by DCs that are exposed to $\mathrm{N}$. brasiliensis-derived $\mathrm{T}_{\mathrm{H}}$ 2-cell-stimulating antigens (A. Balic and R. M. M., unpublished observations). It is possible that these immature DCs might bias responses towards the $\mathrm{T}_{\mathrm{H}} 2$-cell response. However, in human DCs that are matured in the presence of LPS, schistosome-egg antigens do not inhibit the upregulation of expression of these markers and yet the DCs have potent $\mathrm{T}_{\mathrm{H}} 2$-cell-promoting capacity, and so are referred to as DC2s (REF. 92). One noteable feature of DC2s is the expression of OX40 ligand, which is potentially relevant as ligation of OX40 amplifies $\mathrm{T}_{\mathrm{H}}$ 2-cell differentiation ${ }^{93}$. Because DCs are not an essential source of either IL-4 or IL-10 in the induction of helminthskewed $\mathrm{T}_{\mathrm{H}}$ 2-cell responses ${ }^{94}$, the search is still under way for intermediary molecules. One candidate is CCL19 (macrophage inflammatory protein $3 \beta$, MIP $3 \beta$ ), the 
expression of which is induced in DCs by the mosquito-borne infective L3 stage of B. malayi, but not by microparasites ${ }^{95}$, and has been reported to promote the synthesis of IL-10 by human leukocytes.

DCs can, under certain conditions, differentiate into strong inducers of $\mathrm{T}_{\mathrm{Reg}}$ cells $\mathrm{s}^{75}$. For example, if lipid fractions from $S$. mansoni are present during the maturation of human DCs, the DCs become conditioned to induce regulatory activity (such as IL-10 production) by naive T-cell populations ${ }^{96}$. So, regulatory accessory cells can develop under the influence of defined parasite molecules, and it seems that helminths might induce $\mathrm{T}_{\text {Reg }}$ cells through specific APC subsets. FIG. 4 illustrates how the regulatory environment that surrounds helminth infections might be envisaged.

\section{Parasite immunomodulators}

In this section, we examine individual helminth components, in the context of particular roles in immune evasion. We then discuss more generally whether the regulatory mechanisms in the immune system are reacting to selected molecular patterns of helminths, or if

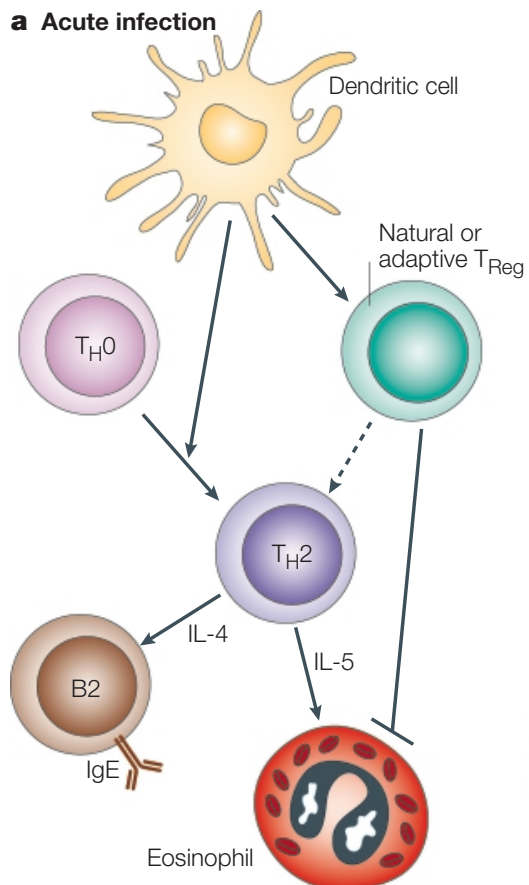

\section{b Chronic infection}

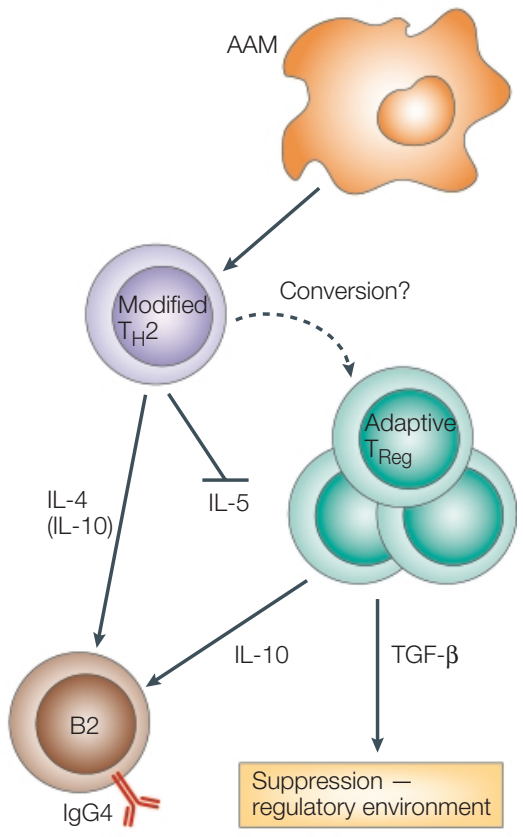

Figure 4 | The regulatory environment that we propose might develop during helminth infection. a | The entry of a parasitic helminth leads to the activation of dendritic cells (DCs) in the peripheral tissues; these cells will express co-stimulatory molecules and react to polarizing signals from helminths. It is known that they initially activate naive T cells to become Thelper $2\left(\mathrm{~T}_{\mathrm{H}} 2\right)$ cells It is also possible that crossreactive helminth antigens might stimulate the involvement of natural regulatory $T\left(T_{\text {Reg }}\right)$ cells. The early involvement of $T_{\text {Reg }}$ cells (natural and/or adaptive) is thought to impede $T_{H} 2$-cell responses, such as interleukin-5 (IL-5)-dependent eosinophil activation, and safeguard against excessive $T_{H} 2$-cell responses. b | With increasing levels of parasite antigens, we postulate that a stronger regulatory network might be established through antigen-specific (adaptive) $T_{\text {e }}$ cells. At this chronic stage of infection, macrophages are known to acquire an alternatively activated phenotype (AAM) that can suppress T-cell proliferation and promote the development of modified $T_{H} 2$ cells. The interactions of DCs and newly differentiating macrophages with $T$ cells in chronic infection are less clear, but the effector arms of the immune system remain in a modified state with, for example, the reduced production of IL-5, and high levels of IL-10 (produced by adaptive $T_{\text {e }}$ cells), which switches B-cell responses to IgG4 and not $\lg \mathrm{E}$, and transforming growth factor- $\beta$ (TGF- $\beta$ ), which mediates cellular hyporesponsiveness. parasites have evolved to direct regulation for their own ends. Our emphasis is largely, but not entirely, on products that are secreted by parasites or otherwise made available to the host immune system by living worms (FIG. 5). This focus helps select from the large genomes of helminths $\left(\sim 20,000\right.$ protein-coding genes $\left.{ }^{97}\right)$ those proteins with maximum impact on host biology that are likely to have evolved, in a controlled manner, precisely to modulate and regulate the host immune system.

Interference with antigen processing. Antigens from extracellular helminth parasites are, it is presumed, presented to the immune system through the MHC class II pathway, with crucial processing steps controlled by intracellular proteases. The filarial nematode B. malayi secretes a cysteine proteinase inhibitor (cystatin, Bm-CPI2), which interferes with two classes of protease in the MHC class II pathway, the papain-like cathepsins B, L and $S$ and the legumain-type asparagine endopeptidase. In an experimental model, these properties enable CPI2 to block the presentation of peptides that are derived from exogenous tetanus toxoid by human B cells ${ }^{98}$. Similar inhibitors have been described from Onchocerca volvulus ${ }^{99}$ and $N$. brasiliensis ${ }^{100}$. Interestingly, nematode cystatins are homologues of mammalian cystatin C, which is highly expressed by immature DCs, then downregulated during DC maturation to allow the transport of mature MHC class II complexes to the cell surface ${ }^{101}$. Parasite cystatins could, therefore, maintain DCs in an immature state in which their antigen-presentation capacity is compromised. Consistent with this hypothesis, the O. volvulus-derived cystatin (onchocystatin) reduces the expression of HLA-DR by human monocytes after 72 hours of co-culture ${ }^{99}$.

Eukaryotic cystatins share a conserved papaininhibiting loop that blocks cathepsins B, L and S. Only certain mammalian cystatins (including cystatin C expressed by DCs) have a second inhibitory site on the opposite face of the molecule, which inactivates asparagine endopeptidase. Notably, this motif is present in the filarial cystatins, and inhibition of asparagine endopeptidase is abolished by site-directed mutagenesis of this motif (J. Murray, B. Manoury, C. Watts and R. M. M., unpublished observations). Because Caenorhabditis elegansderived cystatins inhibit cathepsins, but not asparagine endopeptidase, the filarial homologues might have acquired, through convergent evolution, a new inhibitory property that imitates that of the host and markedly increases the potency of the inhibitor by allowing it to block simultaneously two different classes of protease that are essential for antigen processing.

Modulation of antigen-presenting cells. The effects of cystatins extend beyond the direct inhibition of processing enzymes, as, in the case of onchocystatin at least, they can modulate T-cell proliferation and elicit the upregulation of IL-10 expression ${ }^{99,102}$. So, the cystatins might have an important role in directing and maintaining the altered T-cell phenotype in onchocerciasis. Other modulators from helminths, such as the prostaglandins and other derivatives of membrane arachidonic 


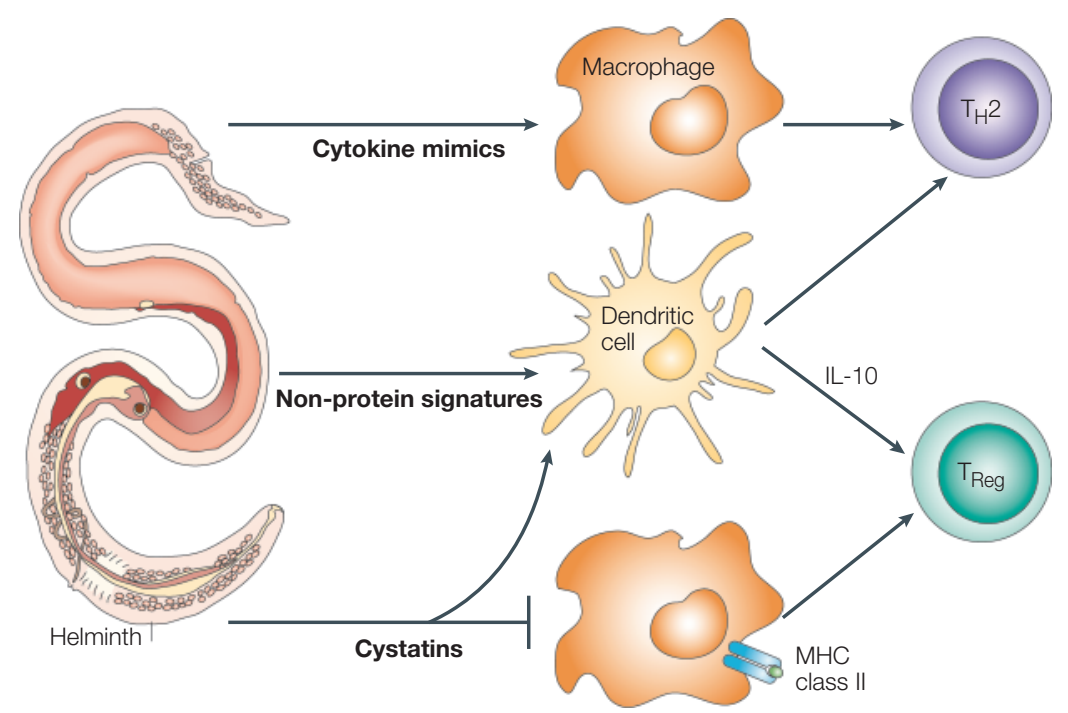

Figure 5 | Immune modulators. Parasite-derived immune modulators function at several levels on crucial immune regulatory cells. Cytokine mimics, such as macrophage-migration inhibition factor (MIF) and transforming growth factor- $\beta$ (TGF- $\beta$ ), that are present in helminths such as Brugia malayi can modulate macrophage function and lead to the induction of T helper $2\left(\mathrm{~T}_{\mathrm{H}} 2\right)$ cells and immune suppression. Non-protein signature molecules (for example, from Schistosoma mansoni) such as phosphatidylserine (PS) and lyso-PS, phosphorylcholine and a range of glycans (such as di-N-acetyl-difucosylated lactose, lacto-N-fucopentaose III and lacto-N-neotetraose) can interact with dendritic cells and result in the induction of both $T_{H} 2$ - and regulatory $T\left(T_{\text {Reg }}\right)$-cell phenotypes. Helminths also produce prostaglandins $\mathrm{PGD}_{2}$ and $\mathrm{PGE}_{2}$, which can have similar effects on accessory cells (not shown). Direct interference with antigen presentation by parasitederived cystatins (such as CPI2 from B. malayi and onchocystatin from Onchocerca volvulus) prevents T-cell activation both at the level of T-cell receptor engagement by peptide-MHC complexes (by inhibiting proteases involved in antigen presentation), and by enhancing the production of interleukin-10 (IL-10) by accessory cells. acid, might have similar roles. For example, the 5-lipoxygenase-dependent production of lipoxin A4 (LXA4) has recently been identified as a crucial step in blocking the production of IL-12 by DCs ${ }^{103}$. Prostaglandins - products of an alternative metabolic pathway from arachidonic acid through cyclo-oxygenases - also influence DCs and macrophages. Prostaglandin $\mathrm{E}_{2}$ $\left(\mathrm{PGE}_{2}\right)$, and more recently $\mathrm{PGD}_{2}$, are known to inhibit the production of IL- 12 by DCs and so act as $\mathrm{T}_{\mathrm{H}} 2$-cellpromoting factors ${ }^{104}$, although $\mathrm{PGD}_{2}$, in particular, also inhibits the efferent migration of skin Langerhans cells after exposure to schistosomes ${ }^{105}$. So, the fact that helminths, such as Taenia taeniaeformis ${ }^{106}$ and B. malayi ${ }^{107}$, synthesize and release $\mathrm{PGE}_{2}$ (other metabolites have yet to be assayed) provides a direct route for immunomodulation of APCs in these parasitic infections. Interestingly, the schistosome vaccine candidate, known as glutathione-S-transferase, is now understood to be a PGD synthase, produced by skin-invading schistosome larvae. As noted earlier, $\mathrm{PGD}_{2}$ would have the effect of blocking the migration of Langerhans cells to the draining lymph nodes, thereby inhibiting a crucial step in the initiation of immunity ${ }^{105}$.

Prostaglandins are not the only helminth-encoded product to affect the activity of APCs. The phosphorylcholine-bearing filarial secreted product ES62 also has the effect of desensitizing mouse peritoneal macrophages to subsequent IFN- $\gamma /$ LPS-induced production of
IL-12, thereby skewing against a $\mathrm{T}_{\mathrm{H}} 1$-cell response $\mathrm{e}^{108}$. Two of the main glycans of schistosome eggs, lacto$\mathrm{N}$-fucopentaose III and lacto- $\mathrm{N}$-neotetraose, are also highly active in inducing macrophages to produce IL-10 and adopt a suppressive phenotype that can block T-cell proliferation ${ }^{109,110}$. Interestingly, both glycans are shared with the mammalian host as they are present in human milk, raising the as-yet-untested possibility that the parasite is engaging in molecular mimicry for the purposes of immune downregulation.

The abundant larval transcript (ALT) proteins are parasite-specific products of $B$. malayi, which are represented by $5 \%$ of the complementary DNA of the invading larva and have no similarity with host proteins. To test whether these are immune-evasion products, we transfected ALT-encoding transcripts into the protozoan parasite Leishmania mexicana, and showed that expression of ALT proteins conferred greater infectivity of bone-marrow-derived macrophages in vitro and accelerated disease in mice in vivo (N. Gomez-Escobar, C. Bennett, L. Prieto-Lafuente, T. Aebischer, C. C. Blackburn and R. M. M., unpublished observations). It, therefore, seems that the ALT proteins are produced by the mosquito-stage parasite and are poised to compromise cell-mediated immunity in a manner that is advantageous to parasite survival.

DCs have been shown to react with defined helminth molecules in two systems. In one, filarial ES62 induces mouse DCs to differentiate towards the DC2 subset, as judged by the cytokine profile of co-cultured naive $\mathrm{T}$ cells $\mathrm{s}^{111}$. As with the studies using schistosome antigens discussed earlier, this functional property was acquired without notable changes in the cell-surface phenotype of the DCs.

In the second model, the lipid fractions from S. mansoni adult worms and eggs were tested on human DCs. Interestingly, material from either lifecycle stage that contained phosphatidylserine resulted not only in DC skewing towards $\mathrm{T}_{\mathrm{H}} 2$-cell induction (in a manner similar to $\mathrm{PGE}_{2}$ ), but also stimulated the development of IL-10-producing $\mathrm{T}_{\mathrm{Reg}}$ cells ${ }^{96}$. In this fraction, it was the lysophosphatidylserine family of molecules (lyso-PS) with acyl chains that are not found in mammalian lyso-PS that were responsible for the induction of $\mathrm{T}_{\mathrm{Reg}}$ cells. This lipid species (lyso-PS) activates DCs through Toll-like receptor 2 (TLR2), providing the first clear evidence that TLRs are involved in the recognition of helminths. In addition to the lyso-PS-TLR2 interaction, many other ligandreceptor pairs are likely to exist between helminths and the immune system. For example, binding between S. mansoni-derived Lewis $\mathrm{x}$ and DC-SIGN (DC-specific intercellular adhesion molecule-grabbing nonintegrin) - a member of the C-type lectin family that is expressed by DCs - has recently been reported ${ }^{112}$. As innate immune cells express a wide variety of C-type lectins, and some helminths that reside in the tissues secrete functional lectins of the same family, there might be a complex interplay between host receptors, parasite glycans and parasite competitor or decoy molecules ${ }^{113}$. 


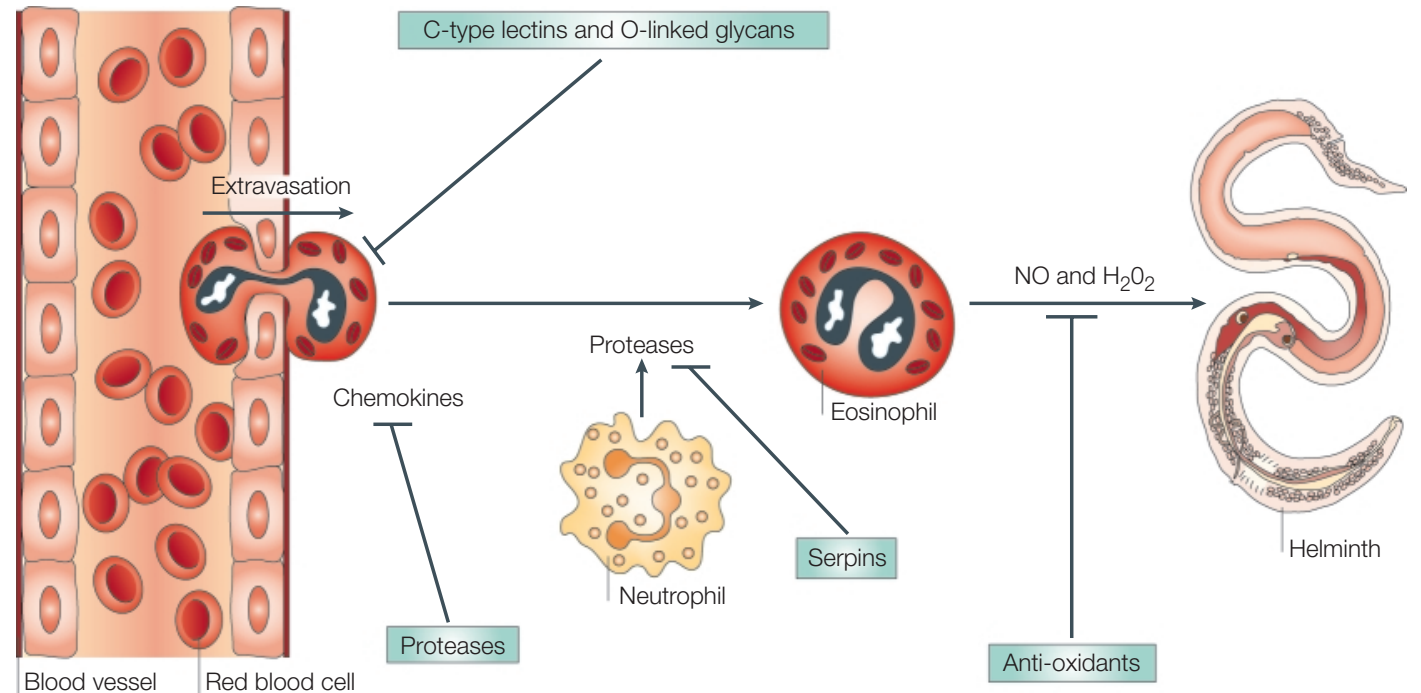

Figure 6 | Blocking efferent immune mechanisms and effector cells. Helminths that reside in the tissues (such as many larval forms and adult worms of Onchocerca) exert a strong anti-inflammatory effect. This might be explained by interference with crucial steps of the immune response, such as extravasation (mediated by leukocyte recognition of endothelial selectins - an interaction that might be blocked by parasite lectins and glycans), chemokine attraction (blocked by parasite protease degradation ${ }^{126}$ ), release of host proteases (inhibited by helminth serpins ${ }^{128}$ ), and potentially lethal attack with reactive nitrogen and oxygen intermediates ( $\mathrm{NO}$ and $\mathrm{H}_{2} \mathrm{O}_{2}$ ) by eosinophils and other cells (inhibited by antioxidants such as glutathione peroxidase, thioperoxidase, superoxide dismutase and glutathione-S-transferase ${ }^{147}$ ).

Cytokine interference and mimicry. Cytokines and chemokines are crucially involved in both innate and adaptive immune responses, so it is not surprising that pathogens have evolved a myriad of strategies to interfere with their function. The two clearest examples in helminths are in gene families that are shared between all multicellular organisms, indicating that helminth parasites have adapted ancestral genes that are present in free-living antecedents to evolve proteins that can interact functionally with host cytokine receptors.

The first helminth cytokines to be found were the homologues of TGF- $\beta$ expressed by the filarial worm B. malay $i^{114,115}$. Two TGF- $\beta$-like proteins are described, one of which $(\mathrm{Bm}-\mathrm{TGH} 2)$ is maximally expressed at the arrested microfilarial stage, is secreted by cultured parasites and binds to the mammalian TGF- $\beta$ receptor ${ }^{115}$. Interestingly, both filarial parasites ${ }^{116}$ and schistosomes ${ }^{117}$ encode members of the TGF- $\beta$ receptor family, and a TGF- $\beta$-like ligand has been noted in the cestode Echinococcus granulosus (C. Fernandez, K. Brehm and R. M. M., unpublished observations), so that all helminth groups might have the potential to exploit TGF- $\beta$-mediated immune downregulation.

The second set of helminth cytokines is comprised of the macrophage-migration inhibition factors (MIFs), which are now known to be produced by numerous nematode parasites including B. malay $i^{118-120}$. Mammalian MIF is a small cytokine with enigmatic properties: synthesized widely by nonhaematopoietic cells, it acts as a pro-inflammatory cytokine in acute settings such as septic shock, inducing the production of TNF by macrophages, for example. B. malayi-encoded MIFs have the same effect on human monocytes as mammalian MIF ${ }^{120}$, which seems to be inconsistent with the anti-inflammatory phenotype of the parasite. Most remarkably, B. malayi-encoded MIF2 was shown by analysis of its crystal structure to be markedly similar to human MIF, and both helminth and human MIF have enzyme activity (dopachrome tautomerase) that is abolished by mutation of a proline residue to glycine (the MIF1G mutant $)^{120}$. We hypothesized that the effect of B. malayi-encoded MIF in vivo, where it is continuously released, might, in fact, be anti-inflammatory, and molecular studies of mammalian MIF show that it can activate an anti-inflammatory pathway through the JAB1 transactivating factor ${ }^{121}$. To support this contention, we found that mice given repeated injections of Bm-MIF1 upregulate the level of YM1 transcripts associated with alternative activation of macrophages, and have a mild eosinophilia; the Bm-MIF1G mutant had no such effect ${ }^{122}$.

Additional cytokine mimics are likely to be found only by functional assays. For example, an IFN- $\gamma$-like protein was reported to be secreted by T. muris ${ }^{123}$. As this parasite is expelled by $\mathrm{T}_{\mathrm{H}}$ 2-cell-derived IL-4 (FIG. 2), such a product is likely to prolong its survival. If there are replica IFN- $\gamma$ molecules, it would be expected that mimics of functional IL-10 have yet to be discovered in helminth genomes, albeit not recognizable at the sequence level. Similarly, chemokine mimics might be too difficult to identify by sequence. However, in a functional test, a neutrophil chemoattractant with chemokine-like binding properties has been found in Ascaris suum ${ }^{124}$. As bioinformatic techniques, such as structural prediction, become more sophisticated, it might be possible to select candidate genes from the ongoing genome sequence projects for functional assays of this nature. 
Blocking of effector mechanisms. Despite the measures described earlier to downmodulate host immunity, it is essential for a successful parasite to have 'last-ditch' defence mechanisms against immune attack. Several such tactics have now been described (FIG. 6). For example, the host chemoattractant platelet activating factor (PAF) is targeted by a complementary enzyme, PAF hydrolase, encoded by $N$. brasiliensis ${ }^{125}$, and eotaxin is degraded by proteases from hookworms ${ }^{126}$, so inhibiting the recruitment of immune cells from the blood. The proteases encoded by the host, such as neutrophil elastase and cathepsin G, are inhibited by the serpin that is released from bloodstream microfilariae of B. malay $i^{127}$, and serpins from many other helminth parasites are mainly expressed in similar circumstances ${ }^{128}$. Antibodies are inverted by Fc-binding molecules on the surface of schistosomes ${ }^{129}$, and the activation of complement is inhibited in infection with E. granulosus by uptake of the host inhibitory factor $\mathrm{H}$ onto the hydatid cyst wall ${ }^{130}$. Reactive oxygen intermediates are dealt with by parasite surface enzymes such as glutathione peroxidase and superoxide dismutase ${ }^{131}$. Now that genetic tools, such as RNA interference, are beginning to be applied successfully to parasitic helminths ${ }^{132-134}$, we can begin to place these diverse products in a functional hierarchy and understand the context for their immunosuppressive roles.

\section{Have helminths evolved to stimulate $\mathbf{T}_{H} \mathbf{2}$ cells}

The fact that $\mathrm{T}_{\mathrm{H}} 2$-cell responses in mice not only protect the host from the pathological consequences of schistosomiasis, but also promote parasite transmission in terms of the egress of eggs into the intestinal lumen, indicates that the switch to $\mathrm{T}_{\mathrm{H}} 2$ cells can benefit both partners in this host-parasite relationship. Extending this argument to the human context, a study reported that schistosome-infected individuals with low $\mathrm{CD} 4^{+}$ T-cell counts owing to HIV co-infection have lower rates of egg excretion ${ }^{135}$. Does the $\mathrm{T}_{\mathrm{H}} 2$-cell response simply reflect an appropriate form of host recognition of helminth parasites or, more controversially, have parasites selectively evolved to stimulate $\mathrm{T}_{\mathrm{H}}$ 2-cell responses for their own advantage. If the former, it might be predicted that common pathogen-associated molecular patterns (PAMPs) will exist for helminths (or at least separately for the three principal phyla of cestodes, nematodes and trematodes). If the latter, then the repeated evolution of parasitism in different lineages of helminth organisms might have resulted in specific and unique molecular strategies for the stimulation of $\mathrm{T}_{\mathrm{H}} 2$ cells in different taxonomic branches.

The search for a helminth equivalent of bacterial LPS or viral double-stranded RNA, possibly acting through a TLR form attuned to multicellular parasites, is one of popularity at present. However, so far, we have identified no generic motif that specifically marks eukaryotic pathogens. Some interesting possibilities remain to be studied, particularly among parasite carbohydrates, and a mechanism that recognizes, for example, the absence of sialic acid from lower invertebrate glycans might also operate. Moreover, the apparent absence of DNA methylation in lower vertebrates (experimentally shown for S. mansoni ${ }^{136}$ ) implies that resulting CpG motifs could trigger pro-inflammatory responses through TLR9 (REF. 137). Although DNA release would only be expected following death of a parasite, attrition of a proportion of incoming larvae always occurs, and so there is opportunity for an interaction at this level.

The argument against a generic helminth PAMP might rest on the various strategies for the induction of $\mathrm{T}_{\mathrm{H}} 2$ cells that are already apparent among parasitic helminths, including the expression of unique proteins that stimulate the production of IL-4. Although the free-living nematode C. elegans elicits a $\mathrm{T}_{\mathrm{H}}$ 2-cell response if injected into mice, its related parasites carry out this feat more potently (J. E. Allen, personal communication). It is possible that from an inherent tendency towards a $\mathrm{T}_{\mathrm{H}}$ 2-cell response, parasitic species might have amplified this capacity to its present level in which secreted proteins from one $\mathrm{T}_{\mathrm{H}}$ 2-driving parasite $\left(N\right.$. brasiliensis) can act as an adjuvant for $\mathrm{T}_{\mathrm{H}} 2$-cell responses ${ }^{138}$. One of the candidate glycan motifs that might give a molecular stamp to helminths is thought to be the $\alpha 3$-fucosylation of a chitobiose $\left(\mathrm{GlcNac}_{2}\right)$ core $^{139}$. So, DCs pulsed with fractions containing this motif or the $\beta 2$-xylosylated core sugar drive strong $\mathrm{T}_{\mathrm{H}} 2$-cell responses in mice ${ }^{140}$. However, the same structures are found not only in C. elegans ${ }^{139}$, but also in host Lewis $\mathrm{x}$, implying that additional structural factors must lend specificity and intensity to the $\mathrm{T}_{\mathrm{H}}$ 2-cell response to helminth glycans.

Taking S. mansoni as another example, proteins, glycans and lipoconjugates can all induce $\mathrm{T}_{\mathrm{H}} 2$ cells. One recombinant protein, IPSE, which is a prominent secreted egg product, can stimulate the release of IL-4 by human basophils ${ }^{141}$. IPSE seems to bind IgE present on the cell surface of basophils, irrespective of antigen specificity, and activates cells by crosslinking. A second recombinant protein, TCTP, also activates basophils in terms of histamine release, although the release of IL-4 was not measured ${ }^{142}$. Notably, from the same source, are the host-like glycans, such as the Lewis X-related carbohydrate lacto- $\mathrm{N}$-fucopentaose III, which when conjugated to human serum albumin, elicits strong $\mathrm{T}_{\mathrm{H}} 2$-cell recall responses (IL-4, IL-5, IL-10 and IgE) in mice ${ }^{143}$. In addition, the lipid fraction from the same eggs induces $\mathrm{T}_{\mathrm{H}}$ 2-cell differentiation, in a manner that is distinct from the stimulation of $\mathrm{T}_{\mathrm{Reg}}$ cells, as only the latter depends on TLR2 (REF. 96). Overall, the example of S. mansoni argues strongly that helminths have evolved directed mechanisms for the induction of $\mathrm{T}_{\mathrm{H}} 2$ cells, rather than passively retained generic features from which the host selects differentiation of this pathway.

\section{Regulatory circuits - a balanced equilibrium?}

The survival of helminth parasites indicates their success in outmanoeuvring the immune system, but we should also note that they frequently succeed in achieving some form of balanced parasitism in which transmission is maintained and acute morbidity avoided. This ideal, homeostatic state almost certainly requires an environment rich in regulatory mechanisms, be they 


\section{IDIOTYPIC NETWORK}

The antigen-binding site of an antibody is an idiotype. As an immune response develops and clonal expansion of B cells occurs, the prevalence of this previously rare idiotype increases and can lead to the development of an antiidiotypic T- and B-cell response.
$\mathrm{T}_{\mathrm{Reg}}$-cell pathways or many of the other modulatory interactions discussed earlier.

We envisage a scenario with both mini-regulatory circuits, such as the IL-13 feedback loop, which produces soluble decoy IL-13 receptor molecules, and more widespread downregulation mediated by systemic production of IL- 10 and TGF- $\beta$. Between these extremes, there might be localized regulators, such as the DC populations in the draining lymph nodes and the alternatively activated NeMacs that are induced in B. malayi infection. Of course, there are in addition many other, independent modulatory connections, and in a clinically asymptomatic individual, it is expected that a combination of these mechanisms might be required, acting together to prevent the pathogenic overshooting of the host immune response.

At this stage, however, it is tempting to suggest that $\mathrm{T}_{\mathrm{Reg}}$ cells will prove to be intimately involved in the immunobiology of helminths. Certainly, the effects of IL-10 extend widely to antibody isotypes, T-cell phenotypes and APC functions, all of which match well with the observed immunological status of typical patients with chronic schistosome or filarial infections. More generally, the 'regulatory environment' model (FIG. 4) revises the hygiene hypothesis, to indicate that both $\mathrm{T}_{\mathrm{H}}$ 2-mediated allergies and $\mathrm{T}_{\mathrm{H}}$ 1-mediated autoimmune diseases can be coordinately controlled by the regulatory arm of APCs and T cells. Moreover, the model can explain the phenomenon of 'wormy individuals', who make up the small percentage of individuals in endemic populations who have particularly high worm burdens. Perhaps the wormy individuals have the strongest regulatory network, resulting in an immune system less prone to allergy and autoimmunity, but more likely to harbour heavy helminth infections.

If there are, as we suggest, regulatory wheels within wheels, any regulatory mechanism must require intricate tuning of parasite molecular structures to host receptors and ligands. No doubt, this will have evolved over long periods of time, and in most cases confer strict host specificity on each species of parasite. Moreover, the areas we have discussed are far from exhaustive. For example, a detailed study of schistosomiasis has provided strong evidence for an IDIOTYPIC NETWORK that regulates hyperresponsiveness ${ }^{144}$, there is evidence that neonatal exposure to parasites induces susceptibility to infection in later life ${ }^{145}$, and there is growing interest in the proinflammatory effects of endosymbiotic bacteria found in most filarial parasites ${ }^{146}$. Future investigations will allow us to integrate these varying strands of regulation and counter-regulation, and thereby devise means of intervention not only to prevent parasite infestation and pathogenesis in particular, but also immunopathological and inflammatory disease in general.
1. Muller, R. In Worms and Human Disease. 1-161 (CABI Publishing, Wallingford, UK, 2002).

2. King, C. L. et al. Cytokine control of parasite-specific anergy in human lymphatic filariasis. Preferential induction of a regulatory Thelper type 2 lymphocyte subset. J. Clin. Invest. 92, 1667-1673 (1993).

3. Yazdanbakhsh, M. et al. T cell responsiveness correlates differentially with antibody isotype levels in clinical and asymptomatic filariasis. J. Infect. Dis. 167, 925-931 (1993).

Grogan, J. L. Kremsner, P. G., Deelder, A. M. \& Yazdanbakhsh, M. Antigen-specific proliferation and interferon- $\gamma$ and interleukin-5 production are downregulated during Schistosoma haematobium infection. J. Infect. Dis. 177, 1433-1437 (1998).

5. Greene, B. M., Fanning, M. M. \& Ellner, J. J. Nonspecific suppression of antigen-induced lymphocyte blastogenesis in Onchocerca volvulus infection in man. Clin. Exp. Immunol. 52, 259-265 (1983)

6. Sabin, E. A., Araujo, M. I., Carvalho, E. M. \& Pearce, E. J. Impairment of tetanus toxoid-specific $T_{H} 1$-like immune responses in humans infected with Schistosoma mansoni. J. Infect. Dis. 173, 269-272 (1996).

7. Cooper, P. J., Espinel, I., Paredes, W., Guderian, R. H. \& Nutman, T. B. Impaired tetanus-specific cellular and humoral responses following tetanus vaccination in human onchocerciasis: a possible role for interleukin-10. J. Infect. Dis. 178, 1133-1138 (1998)

8. Liwski, R., Zhou, J., McAlister, V. \& Lee, T. D. Prolongation of allograft survival by Nippostrongylus brasiliensis is associated with decreased allospecific cytotoxic T lymphocyte activity and development of T cytotoxic cell type 2 cells. Transplantation 69, 1912-1922 (2000).

9. King, C. L., Connelly, M., Alpers, M. P., Bockarie, M. \& Kazura, J. W. Transmission intensity determines lymphocyte responsiveness and cytokine bias in human lymphatic filariasis. J. Immunol. 166, 7427-7436 (2001).

10. Fox, J. G. et al. Concurrent enteric helminth infection modulates inflammation and gastric immune responses and reduces helicobacter-induced gastric atrophy. Nature Med. 6, 536-542 (2000).

11 Nacher, M. et al. Helminth infections are associated with protection from malaria-related acute renal failure and jaundice in Thailand. Am. J. Trop. Med. Hyg. 65, 834-836 (2001)
12 van den Biggelaar, A. et al. Decreased atopy in children infected with Schistosoma haematobium: a role for parasiteinduced interleukin-10. Lancet 356, 1723-1727 (2000). induced interleukin-10. Lancet $356,1723-1727$ (2000). The first report to link interleukin-10 (IL-10) respons
to parasites with a downregulation of allergic to parasites with a downregulation of allergic
responses in helminth-infected humans.

13 Yazdanbakhsh, M., van den Biggelaar, A. \& Maizels, R. M. $T_{H} 2$ responses without atopy: immunoregulation in chronic helminth infections and reduced allergic disease. Trends Immunol. 22, 372-377 (2001).

14 Yazdanbakhsh, M., Kremsner, P. G. \& van Ree, R. Allergy, parasites, and the hygiene hypothesis. Science $\mathbf{2 9 6}$, parasites, and the

15 Sher, A. F. \& Coffman, R. L. Regulation of immunity to parasites by T cells and T cell-derived cytokines. Annu. Rev. Immunol. 10, 385-409 (1992).

16 Maizels, R. M., Bundy, D. A. P., Selkirk, M. E., Smith, D. F. \& Anderson, R. M. Immunological modulation and evasion by helminth parasites in human populations. Nature $\mathbf{3 6 5}$, 797-805 (1993).

17 Mohrs, M., Shinkai, K., Mohrs, K. \& Locksley, R. M. Analysis of type 2 immunity in vivo with a bicistronic IL-4 reporter. Immunity 15, 303-311 (2001).

18 Pearce, E. J. \& MacDonald, A. S. The immunobiology of schistosomiasis. Nature Rev. Immunol. 2, 499-511 (2002)

19 Osborne, J. \& Devaney, E. The L3 of Brugia induces a $\mathrm{T}_{\mathrm{H}}$ 2-polarized response following activation of an IL-4producing CD4- CD8- $\alpha \beta$ T cell population. Int. Immunol. 10, 1583-1590 (1998).

20 Jarrett, E. E. E. Potentiation of rat reagenic (lgE) antibody to ovalbumin in the rat following sequential trematode and nematode infections. Immunol. 22, 1099-1101 (1972).

21 Kullberg. M. C. Pearce, E. J., Hieny, S. E., Sher, A. \& Berzofsky, J. A. Infection with Schistosoma mansoni alters $\mathrm{T}_{\mathrm{H}} 1 / \mathrm{T}_{\mathrm{H}} 2$ cytokine responses to a non-parasite antigen. J. Immunol. 148, 3264-3270 (1992).

22 Liu, Z., et al. Nippostrongylus brasiliensis can induce B7-independent antigen-specific development of IL-4-producing T cells from naive CD4 ${ }^{+} T$ cells in vivo. J. Immunol. 169, 6959-6968 (2002).

23 Lawrence, R. A., Allen, J. E., Osborne, J. \& Maizels, R. M. Adult and microfilarial stages of the filarial parasite Brugia malayi stimulate contrasting cytokine and immunoglobulin malayi stimulate contrasting cytokine and immunoglo 1216-1224 (1994).
24 Else, K. J., Finkelman, F. D., Maliszewski, C. R. \& Grencis, R. K. Cytokine-mediated regulation of chronic intestinal helminth infection. J. Exp. Med. 179, 347-351 (1994).

25 Hagan, P., Blumenthal, U. J., Dunn, D., Simpson, A. J. G. \& Wikins, H. A. Human IgE, IgG4 and resistance to reinfection with Schistosoma haematobium. Nature 349, 243-245 (1991).

26 Elson, L. H., et al. Immunity to onchocerciasis: putative immune persons produce $a T_{H} 1$-like response to Onchocerca volvulus. J. Infect. Dis. 171, 652-658 (1995).

27 Finkelman, F. D., et al. Cytokine regulation of host defense against parasitic gastrointestinal nematodes: lessons from studies with rodent models. Annu. Rev. Immunol. 15 505-533 (1997).

28 Maizels, R. M. \& Holland, M. J. Parasite immunity: pathways for expelling intestinal parasites. Curr. Biol. 8, R711-R714 (1998).

29 Urban, J. F., Jr. et al. IL-13, IL-4R $\alpha$ and Stat6 are required for the expulsion of the gastrointestinal nematode parasite Nippostrongylus brasiliensis. Immunity 8, 255-264 (1998). A definitive study of the type-2 mediators and signalling components that generate protective immunity to a gut nematode.

30 Vallance, B. A. \& Collins, S. M. The effect of nematode infection upon intestinal smooth muscle function. Parasite Immunol. 20, 249-253 (1998).

31 Faulkner, H., Renauld, J.-C., Van Snick, J. \& Grencis, R. K. Interleukin-9 enhances resistance to the intestinal nematode Trichuris muris. Infect. Immun. 66, 3832-3840 (1998).

32 Urban, J. F., Jr, Noben-Trauth, N., Schopf, L., Madden, K. B. \& Finkelman, F. D. IL-4 receptor expression by non-bone marrow-derived cells is required to expel gastrointestinal marrow-derived cells is required to expel gastrointest nemato $(2001)$.

33 Lawrence, R. A., Allen, J. E., Gregory, W. F., Kopf, M. \& Maizels, R. M. Infection of IL-4 deficient mice with the parasitic nematode Brugia malayi demonstrates that host resistance is not dependent on a $\mathrm{T}_{2} 2$ dominated immune response. J. Immunol. 154, 5995-6001 (1995).

34 Dent, L. A., et al. Interleukin-5 transgenic mice show enhanced resistance to primary infections with Nippostrongylus brasiliensis but not primary infections
Nith with Toxocara canis. Infect. Immun. 67, 989-993 with Toxoc 
35 Herbert, D. R. et al. Role of IL-5 in innate and adaptive immunity to larval Strongyloides stercoralis in mice. J. Immunol. 165, 4544-4551 (2000).

36 Meeusen, E. N. T. \& Balic, A. Do eosinophils have a role in the killing of helminth parasites? Parasitol. Today 16, 95-10 (2000).

37 Caulada-Benedetti, Z., Al-Zamel, F., Sher, A. \& James, S. Comparison of $T_{H} 1$ - and $T_{H} 2$-associated immune reactivities stimulated by single versus multiple vaccination of mice with irradiated Schistosoma mansoni cercariae. J. Immunol. 146, 1655-1660 (1991).

38 Hoffmann, K. F., James, S. L., Cheever, A. W. \& Wynn, T. A Studies with double cytokine-deficient mice reveal that highly polarized $\mathrm{T}_{H} 1$ - and $\mathrm{T}_{H} 2$-type cytokine and antibody responses contribute equally to vaccine-induced immunity to Schistosoma mansoni. J. Immunol. 163, 927-938 (1999).

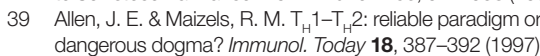

40 Artis, D. et al. Tumor necrosis factor- $\alpha$ is a critical component of interleukin 13-mediated protective T helper cell type 2 responses during helminth infection. J. Exp. Med 190, 953-962 (1999).

41 Lawrence, C. E. et al. IL-4-regulated enteropathy in an intestinal nematode infection. Eur. J. Immunol. 28 2672-2684 (1998).

42 Brunet, L. R., Dunne, D. W. \& Pearce, E. J. Cytokine interaction and immune responses during Schistosoma mansoni infection. Parasitol. Today 14, 422-427 (1998).

43 Hoffmann, K. F., Cheever, A. W. \& Wynn, T. A. IL-10 and the dangers of immune polarization: excessive type 1 and type 2 cytokine responses induce distinct forms of lethal immunopathology in murine schistosomiasis. J. Immunol. 164, 6406-6416 (2000)

\section{Important experimental evidence showing that} regulation protects infected animals against 'overzealous' immune responses of either type 1 or type 2

44 Hoffmann, K. F., Wynn, T. A. \& Dunne, D. W. Cytokinemediated host responses during schistosome infections; walking the fine line between immunological control and immunopathology. Adv. Parasitol. 52, 265-307 (2002).

45 Shimizu, J., Yamazaki, S., Takahashi, T., Ishida, Y. \& Sakaguchi, S. Stimulation of $\mathrm{CD} 25^{+} \mathrm{CD} 4^{+}$regulatory $\mathrm{T}$ cells through GITR breaks immunological self-tolerance. Nature Immunol. 3, 135-142 (2002).

46 Shevach, E. M. CD4 $4^{+} \mathrm{CD} 25^{+}$suppressor T cells: more questions than answers. Nature Rev. Immunol. 2, 389-400 (2002).

47 Brunet, L. R., Finkelman, F. D., Cheever, A. W., Kopf, M. A. 8 Pearce, E. J. IL-4 protects against TNF- $\alpha$-mediated cachexia and death during acute schistosomiasis. J. Immunol. 159, 777-785 (1997).

48 MacDonald, A. S., Araujo, M. I. \& Pearce, E. J. Immunology of parasitic helminth infections. Infect. Immun. 70, 427-433 (2002).

49 Chiaramonte, M. G., et al. IL-13 is a key regulatory cytokine for $\mathrm{T}_{H} 2$ cell-mediated pulmonary granuloma formation and IgE responses induced by Schistosoma mansoni eggs. J. Immunol. 162, 920-930 (1999).

50 Fallon, P. G., Richardson, E. J., McKenzie, G. J. \& McKenzie, A. N. J. Schistosome infection of transgenic mice defines distinct and contrasting pathogenic roles for IL-4 and IL-13: IL-13 is a profibrotic agent. J. Immunol. 164. 2585-2591 (2000).

51 Platts-Mills, T., Vaughan, J., Squillace, S., Woodfolk, J. \& Sporik, R. Sensitisation, asthma, and a modified T. response in children exposed to cat allergen: a population-

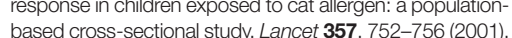
Conceptually important work in allergy, which might Conceptually important work in allergy, which might
indicate parallels for the immunology of helminth indicate para

52 Jeannin, P., Lecoanet, S., Delneste, Y., Gauchat, J. -F. \& Bonnefoy, J. -Y. IgE versus IgG4 production can be differentially regulated by IL-10. J. Immunol. 160 3555-3561 (1998).

53 Maizels, R. M. et al. T cell activation and the balance of antibody isotypes in human filariasis. Parasitol. Today 11 50-56 (1995).

54 Sartono, E., Kruize, Y. C. M., Kurniawan-Atmadja, A. Maizels, R. M. \& Yazdanbakhsh, M. Depression of antigenspecific interleukin- 5 and interferon- $\gamma$ responses in human lymphatic filariasis as a function of clinical status and age. J. Infect. Dis. 175, 1276-1280 (1997).

55 Cooper, P. J. et al. Early human infection with Onchocerca volvulus is associated with an enhanced parasite-specific cellular immune response. J. Infect. Dis. 183, 1662-1668 (2001).

56 Boros, D. L., Pelley, R. P. \& Warren, K. S. Spontaneous modulation of granulomatous hypersensitivity in
Schistosomiasis mansoni. J. Immunol. 114, 1437-1441 (1975).
57 Chiaramonte, M. G. et al. Regulation and function of the interleukin 13 receptor $\alpha 2$ during a Thelper cell type 2 dominant immune response. J. Exp. Med. 197, 687-701 (2003).

58 Le Goff, L., Lamb, T. J., Graham, A. L., Harcus, Y. \& Allen, J. E. IL-4 is required to prevent filarial nematode development in resistant but not susceptible strains of mice. Int. J. Parasitol. 32, 1277-1284 (2002).

59 Maizels, R. M. \& Lawrence, R. A. Immunological tolerance: the key feature in human filariasis? Parasitol. Today $\mathbf{7}$, 271-276 (1991).

60 Sher, A. et al. Role of T-cell derived cytokines in the downregulation of immune responses in parasitic and retroviral infection. Immunol. Rev. 127, 183-204 (1992).

61 Schopf, L. R., Hoffmann, K. F., Cheever, A. W., Urban, J. F., Jr \& Wynn, T. A. IL-10 is critical for host resistance and survival during gastrointestinal helminth infection. J. Immunol. 168, 2383-2392 (2002).

62 Wynn, T. A. et al. IL-10 regulates liver pathology in acute murine Schistosomiasis mansoni but is not required for immune down-modulation of chronic disease. J. Immuno. 159, 4473-4480 (1998)

63 Sadler, C. H., Rutitzky, L. I., Stadecker, M. J. \& Wilson, R. A. $\mathrm{IL}-10$ is crucial for the transition from acute to chronic disease state during infection of mice with Schistosoma mansoni. Eur. J. Immunol. 33, 880-888 (2003).

64 Mahanty, S. et al. High levels of spontaneous and parasite antigen-driven interleukin-10 production are associated with antigen-specific hyporesponsiveness in human lymphatic filariasis. J. Infect. Dis. 173, 769-773 (1996).

65 Mahanty, S. et al. Regulation of parasite antigen-driven immune responses by interleukin-10 (IL-10) and IL-12 in Iymphatic filariasis. Infect. Immun. 65, 1742-1747 (1997).

66 Doetze, A. et al. Antigen-specific cellular hyporesponsiveness in a chronic human helminth infection is mediated by $T_{H} 3 / T_{R} 1$-type cytokines IL-10 and transforming growth factor- $\beta$ but not by a $T_{H} 1$ to $T_{H} 2$ shift. Int. Immunol. 12, 623-630 (2000).

\section{The first evidence for regulatory T-cell activity in} human helminth infection.

67 Araújo, M. I. et al. Evidence of a Thelper type 2 activation in human schistosomiasis. Eur. J. Immunol. 26, 1399-1403 (1996).

68 King, C. L. et al. Cytokine control of parasite-specific anergy in human urinary schistosomiasis. IL-10 modulates Iymphocyte reactivity. J. Immunol. 156, 4715-4721 (1996). One of the most comprehensive studies on cellular and cytokine responses in a human helminth-infected population, emphasizing the role of IL-10 at an early stage.

69 Grogan, J.L. Kremsner P. G. Deelder, A. M. \& Yazdanbakhsh, M. The effect of anti-IL-10 on proliferation and cytokine production in human schistosomiasis: fresh versus cryopreserved cells. Parasite Immunol. 20, 345-349 (1998).

70 Satoguina, J. et al. Antigen-specific T regulatory-1 cells are associated with immunosuppression in a chronic helmint infection (onchocerciasis). Microbes Infect. 4, 1291-1300 (2002).

71 Steel, C. \& Nutman, T. B. CTLA-4 in filarial infections: implications for a role in diminished $\mathrm{T}$ cell reactivity. J. Immunol. 170, 1930-1938 (2003).

72 Bluestone, J. A. \& Abbas, A. K. Natural versus adaptiv regulatory T cells. Nature Rev. Immunol. 3, 253-257 (2003).

73 Cogulatory T cells. Nature Rev. Immunol. 3, 253-257 Bacterial-reactive $T$ regulatory cells inhibit pathogenic immune responses to the enteric flora. J. Immunol. 169 6112-6119 (2002)

74 McGuirk, P. \& Mills, K. Pathogen-specific regulatory T cells provoke a shift in the $T_{H} 1 / T_{H} 2$ paradigm in immunity to infectious diseases. Trends Immunol. 23, 450-455 (2002).

75 McGuirk, P., McCann, C. \& Mills, K. H. G. Pathogen-specific T regulatory 1 cells induced in the respiratory tract by a bacterial molecule that stimulates interleukin-10 production by dendritic cells: a novel strategy for evasion of protective Thelper type 1 responses by Bordetella pertussis. J. Exp. Thelper type 1 responses by

76 Belkaid, Y. Piccirillo, C. A., Mendez, S., Shevach, E. M. \& Sacks, D. L. CD $4^{+}$CD25 $25^{+}$regulatory T cells control Leishmania major persistence and immunity. Nature 420,

77 Reis e Sousa, C. Dendritic cells as sensors of infection. Immunity 14, 495-498 (2001).

78 Piessens, W. F. et al. Antigen specific suppressor cells and suppressor factors in human filariasis with Brugia malayi. New. Eng. J. Med. 302, 833-837 (1980).

79 Lammie, P. J. \& Katz, S. P. Immunoregulation in experimental filariasis. I. In vitro suppression of mitogeninduced blastogenesis by adherent cells from jirds induced blastogenesis by adherent cells from jirds 1381-1385 (1983).
80 Osborne, J. \& Devaney, E. Interleukin-10 and antigenpresenting cells actively suppress $T_{H} 1$ cells in BALB/c mice infected with the filarial parasite Brugia pahangi. Infect. mmun. 67, 1599-1604 (1999).

81 Flores Villanueva, P. O., Harris, T. S., Ricklan, D. E. \& Stadecker, M. J. Macrophages from schistosomal egg granulomas induce unresponsiveness in specific cloned $\mathrm{T}_{4} 1$ lymphocytes in vitro and downregulate schistosomal granulomatous disease in vivo. J. Immunol. 152 1847-1855 (1994).

82 Allen, J. E. \& Loke, P. Divergent roles for macrophages in Iymphatic filariasis. Parasite Immunol. 23, 345-352 (2001).

83 MacDonald, A. S., Maizels, R. M., Lawrence, R. A. Dransfield, I. \& Allen, J. E. Requirement for in vivo production of IL-4, but not IL-10, in the induction of proliferative suppression by filarial parasites. J. Immunol. 160, 4124-4132 (1998).

84 Allen, J. E. \& MacDonald, A. S. Profound suppression of cellular proliferation mediated by the secretions of nematodes. Parasite Immunol. 20, 241-247 (1998).

85 Loke, P. et al. IL-4 dependent alternatively activated macrophages have a distinctive in vivo gene expression macrophages have a distinctive in vivo gentype. BMC Immunol. 3, 7 (2002).

phenotype. BMC Immunol. 3, 7 (2002).
This paper describes a new gene-expression profile, including YM1 and FIZZ1, in nematode-elicited (alternatively activated) macrophages with the functional capacity to suppress target-cell proliferation.

86 Nair, M. G., Cochrane, D. W. \& Allen, J. E. Macrophages in chronic type 2 inflammation have a novel phenotype characterized by the abundant expression of Ym1 and Fizz1 that can be partly replicated in vitro. Immunol. Lett. $\mathbf{8 5}$ 173-180 (2003).

87 Loke, P., MacDonald, A. S., Robb, A., Maizels, R. M. \& Allen, J. E. Alternatively activated macrophages induced by nematode infection inhibit proliferation via cell to cell contact Eur. J. Immunol. 30, 2669-2678 (2000).

88 Allen, J. E., Lawrence, R. A. \& Maizels, R. M. Antigen presenting cells from mice harboring the filarial nematode,
Brugia malayi, prevent cellular proliferaton but not cytokine production. Int. Immunol. 8, 143-151 (1996).

89 Gordon, S. Alternative activation of macrophages. Nature Rev. Immunol. 3, 23-35 (2003).

90 Jankovic, D., Liu, Z. \& Gause, W. C. T. 1- and T, 2-cell commitment during infectious disease: asymmetry in divergent pathways. Trends Immunol. 22, 450-457 (2001).

91 MacDonald, A. S., Straw, A. D., Bauman, B. \& Pearce, E. J. CD8- dendritic cell activation status plays an integral role in influencing $\mathrm{T}_{H} 2$ response development. J. Immunol. 167, 1982-1988 (2001).

92 de Jong, E. C. et al. Microbial compounds selectively induce $\mathrm{T}_{\mathrm{H}} 1$ cell-promoting or $\mathrm{T}_{\mathrm{H}} 2$ cell-promoting dendritic cells in vitro with diverse $\mathrm{T}_{4}$ cell-polarizing signals. J. Immunol. 168, 1704-1709 (2002).

93 Flynn, S., Toellner, K.-M. Raykundalia C. Goodall, M. \& Lane, P. CD4 ${ }^{+} T$ cell cytokine differentiation: the $B$ cell activation molecule, OX40 ligand, instructs $\mathrm{CD} 4^{+} \mathrm{T}$ cells to express interleukin 4 and upregulates expression of the chemokine receptor, Blr-1. J. Exp. Med. 188, 297-304 (1998)

94 MacDonald, A. S. \& Pearce, E. J. Polarized $T_{H}$ cell response induction by transferred antigen-pulsed dendritic cells is dependent on IL-4 or IL-12 production by recipient cells. J. Immunol. 168, 3127-3130 (2002).

95 Chaussabel, D. et al. Unique gene expression profiles of human macrophages and dendritic cells to phylogenetically distinct parasites. Blood 102, 672-681 (2003).

96 van der Kleii, D. et al. A novel host - parasite lipid cross talk: schistosomal lysophosphatidylserine activates Toll-like receptor 2 and affects immune polarization. J. Biol. Chem. 277, 48122-48129 (2002)

\section{Evidence for the induction of both $\mathrm{T}$ helper $2\left(\mathrm{~T}_{\mathrm{H}} 2\right)$} cells and regulatory $T$ cells through Toll-like receptor (TLR) signalling in response to schistosome-specific lipid structures.

97 Blaxter, M. L., Aslett, M., Guiliano, D. \& Daub, J. Parasitic helminth genomics. Filarial genome project. Parasitol. 118 S39-S51 (1999).

98 Manoury, B., Gregory, W. F., Maizels, R. M. \& Watts, C. $\mathrm{Bm}$-CPI-2, a cystatin homolog secreted by the filarial parasite Brugia malayi, inhibits class II MHC-restricted antigen processing. Curr. Biol. 11, 447-451 (2001).

99 Schönemeyer, A. et al. Modulation of human T cell responses and macrophage functions by onchocystatin, a secreted protein of the filarial nematode Onchocerca volvulus. J. Immunol. 167, 3207-3215 (2001).

100 Dainichi, T. et al. Nippocystatin, a cysteine protease inhibito from Nippostrongy/us brasiliensis, inhibits antigen processing and modulates antigen-specific immun response. Infect. Immun. 69, 7380-7386 (2001). 
101 Pierre, P. \& Mellman, I. Developmental regulation of invariant chain proteolysis controls MHC class II trafficking in mouse dendritic cells. Cel/ 93, 1135-1145 (1998)

102 Hartmann, S., Kyewski, B., Sonnenburg, B. \& Lucius, R. A filarial cysteine protease inhibitor downregulates $T$ cell proliferation and enhances interleukin-10 production. Eur. $J$ Immunol. 27, 2253-2260 (1997).

103 Aliberti, J., Hieny, S., Reis e Sousa, C., Serhan, C. N. \& Sher, A. Lipoxin-mediated inhibition of IL-12 production by DCs: a mechanism for regulation of microbial immunity. Nature Immunol. 3, 76-82 (2002).

104 Kalinski, P., Hilkens, C. M., Snijders, A., Snijdewint, F. G. \& Kapsenberg, M. L. IL-12-deficient dendritic cells, generated in the presence of prostaglandin E2, promote type 2 cytokine production in maturing human naive Thelper cells. J. Immunol. 159, 28-35 (1997)

105 Angeli, V. et al. Role of the parasite-derived prostaglandin D2 in the inhibition of epidermal Langerhans cell migration during schistosomiasis infection. J. Exp. Med. 193 1135-1147 (2001).

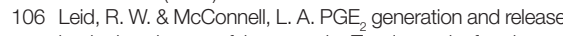
by the larval stage of the cestode, Taenia taeniaeformis. Prostaglandins Leukot. Med. 11, 317-323 (1983).

107 Liu, L. X., Buhlmann, J. E. \& Weller, P. F. Release of prostaglandin $\mathrm{E}_{2}$ by microfilariae of Wuchereria bancrofti and Brugia malayi. Am. J. Trop. Med. Hyg. 46, 520-523 (1992).

108 Goodridge, H. S. et al. Modulation of macrophage cytokine production by ES-62, a secreted product of the filarial nematode Acanthocheilonema viteae. J. Immunol. 167, 940-945 (2001).

109 Atochina, O., Daly-Engel, T., Piskorska, D., McGuire, E. \& Harn, D. A. A schistosome-expressed immunomodulatory glycoconjugate expands peritoneal $\mathrm{Gr} 1^{+}$macrophages that suppress naive $\mathrm{CD} 4^{+} \mathrm{T}$ cell proliferation via an IFN- $\gamma$ and nitric oxide-dependent mechanism. J. Immunol. 167 nitric oxide-depend

110 Terrazas, L. I., Walsh, K. L., Piskorska, D., McGuire, E. \& Harn, D. A., Jr. The schistosome oligosaccharide lacto- $\mathrm{N}-$ neotetraose expands $\mathrm{Gr} 1^{+}$cells that secrete antinflammatory cytokines and inhibit proliferation of naive CD4 cells: a potential mechanism for immune polarization in helminth infections. J. Immunol. 167, 5294-5303 (2001)

111 Whelan, M. et al. A filarial nematode-secreted product signals dendritic cells to acquire a phenotype that drives development of T 2 cells. J. Immunol. 164, 6453-6460 (2000).

112 Van Die, I. et al. The dendritic cell specific C-type lectin DC-SIGN is a receptor for Schistosoma mansoni egg antigens and recognizes the glycan antigen Lewis-x. Glycobiol. 13, 471-478 (2003).

113 Loukas, A. \& Maizels, R. M. Helminth C-type lectins and hostparasite interactions. Parasitol. Today 16, 333-339 (2000).

114 Gomez-Escobar, N., Lewis, E. \& Maizels, R. M. A novel member of the transforming growth factor- $\beta$ (TGF- $\beta$ ) superfamily from the filarial nematodes Brugia malayi and B. pahangi. Exp. Parasitol. 88, 200-209 (1998).

115 Gomez-Escobar, N., Gregory, W. F. \& Maizels, R. M. Identification of $B m$-tgh-2, a filarial nematode homolog of $C$. elegans daf- 7 and human TGF- $\beta$, expressed in microfilaria C. elegans daf-7 and human TGF- $\beta$, expressed in micr
and adult stages of Brugia malayi. Infect. Immun. $\mathbf{6 8}$, and adult stages of

116 Gomez-Escobar, N., van den Biggelaar, A. \& Maizels, R. M. A member of the TGF- $\beta$ receptor gene family in the parasitic nematode Brugia. Gene 199, 101-109 (1997)

117 Davies, S. J., Shoemaker, C. B. \& Pearce, E. J. A divergent member of the transforming growth factor- $\beta$ receptor famil from Schistosoma mansoni is expressed on the parasite surface membrane. J. Biol. Chem. 273, 11234-11240 (1998).

118 Pastrana, D. V. et al. Filarial nematode parasites secrete a homologue of the human cytokine macrophage migration inhibitory factor. Infect. Immun. 66, 5955-5963 (1998).
119 Pennock, J. L. et al. Rapid purification and characterization of L-dopachrome-methyl ester tautomerase (macrophagemigration-inhibitory factor) from Trichinella spiralis, Trichuris muris and Brugia pahangi. Biochem. J. 335, 495-498 (1998).

120 Zang, X. X. et al. Homologues of human macrophage migration inhibitory factor from a parasitic nematode: gene cloning, protein activity and crystal structure. J. Biol. Chem. 277, 44261-44267 (2002)

121 Kleemann, R. et al. Intracellular action of the cytokine MIF to modulate AP-1 activity and the cell cycle through Jab1. Nature 408, 211-216 (2000).

122 Falcone, F. H. et al. A Brugia malayi homolog of macrophage migration inhibitory factor reveals an important link between macrophages and eosinophil recruitment during nematode infection. J. Immunol. 167, 5348-5354 (2001).

123 Grencis, R. K. \& Entwistle, G. M. Production of an interferon- $\gamma$ homologue by an intestinal nematode: functionally significant or interesting artefact. Parasitol. 115, S101-S105 (1997).

124 Falcone, F. H. et al. Ascaris suum-derived products induce human neutrophil activation via a $\mathrm{G}$ protein-coupled receptor that interacts with the interleukin-8 receptor pathway. Infect. Immun. 69, 4007-4018 (2001).

125 Blackburn, C. C. \& Selkirk, M. E. Inactivation of platelet activating factor by a putative acetylhydrolase from the gastrointestinal nematode parasite Nippostrongylus brasiliensis. Immunol. 75, 41-46 (1992).

126 Culley, F. J. et al. Eotaxin is specifically cleaved by hookworm metalloproteases preventing its action in vitro and in vivo. J. Immunol. 165, 6447-6453 (2000).

127 Zang, X. X., Yazdanbakhsh, M., Kiang, H., Kanost, M. R. \& Maizels, R. M. A novel serpin expressed by the blood-borne microfilariae of the parasitic nematode Brugia malayi inhibits human neutrophil serine proteinases. Blood $\mathbf{9 4}, 1418-1428$ human
(1999).

128 Zang, X. \& Maizels, R. M. Serine proteinase inhibitors from nematodes and the arms race between host and pathogen. Trends Biochem. Sci. 26, 191-197 (2001).

129 Loukas, A., Jones, M. K., King, L. T., Brindley, P. J. \& McManus, D. P. Receptor for Fc on the surfaces of schistosomes. Infect. Immun. 69, 3646-3651 (2001).

130 Díaz, A., Ferreira, A. \& Sim, R. B. Complement evasion by Echinococcus granulosus. Sequestration of host factor $\mathrm{H}$ in the hydatid cell wall. J. Immunol. 158, 3779-3786 (1997).

131 Selkirk, M. E., Smith, V. P., Thomas, G. R. \& Gounaris, K. Resistance of filarial nematode parasites to oxidative stress. Int. J. Parasitol. 28 , 1315-1332 (1998)

132 Hussein, A. S., Kichenin, K. \& Selkirk, M. E. Suppression of secreted acetylcholinesterase expression in Nippostrongylus brasiliensis by RNA interference. Mol. Biochem. Parasitol. 122, 91-94 (2002).

133 Aboobaker, A. A. \& Blaxter, M. L. Use of RNA interference to investigate gene function in the human filarial nematode parasite Brugia malayi. Mol. Biochem. Parasitol. 129, 41-51 (2003).

134 Boyle, J. P., Wu, X. J., Shoemaker, C. B. \& Yoshino, T. P. Using RNA interference to manipulate endogenous gene expression in Schistosoma mansoni sporocysts. Mol.
ens. Biochem. Parasitol. 128, 205-215 (2003).

135 Karanja, D. M., Colley, D. G., Nahlen, B. L., Ouma, J. H. \& Secor, W. E. Studies on schistosomiasis in western Kenya: I. Evidence for immune-facilitated excretion of schistosom eggs from patients with Schistosoma mansoni and human immunodeficiency virus coinfections. Am. J. Trop. Med. Hyg. 56, 515-521 (1997).

136 Fantappie, M. R., Gimba, E. R. \& Rumjanek, F. D. Lack of DNA methylation in Schistosoma mansoni. Exp. Parasitol. 98, 162-166 (2001).

$137 \mathrm{Hemmi}$, H. et al. A Toll-like receptor recognizes bacteria DNA. Nature 408, 740-745 (2000).
138 Holland, M. J., Harcus, Y. M., Riches, P. L. \& Maizels, R. M. Proteins secreted by the parasitic nematode Nippostrongylus brasiliensis act as adjuvants for $\mathrm{T}_{\mathrm{H}} 2$ responses. Eur. J. Immunol. 30, 1977-1987 (2000).

139 van Die, l. et al. Core $\alpha 1$-> 3 -fucose is a common modification of $\mathrm{N}$-glycans in parasitic helminths and constitutes an important epitope for lgE from Haemonchus contortus infected sheep. FEBS Lett. 463, 189-193 (1999).

140 Faveeuw, C. et al. Schistosome N-glycans containing core $\alpha 3$-fucose and core $\beta 2$-xylose epitopes are strong inducers of T. 2 responses in mice. Eur. J. Immunol. 33, 1271-1281 (2003)

141 Schramm, G. et al. Molecular characterization of an interleukin-4-inducing factor from Schistosoma manson eggs. J. Biol. Chem. 278, 18384-18392 (2003). The first recombinant protein from helminths associated with the induction of $T_{H} 2$ cells shown to operate by activating mast cells in an IgEindependent manner.

142 Rao, K. V., Chen, L., Gnanasekar, M. \& Ramaswamy, K. Cloning and characterization of a calcium-binding, histamine-releasing protein from Schistosoma mansoni. J. Biol. Chem. 277, 31207-31213 (2002).

143 Okano, M., Satoskar, A. R., Nishizaki, K. \& Harn, D. A., Jr. Lacto-N-fucopentaose III found on Schistosoma mansoni egg antigens functions as adjuvant for proteins by inducing $\mathrm{T}_{\mathrm{H}}$ 2-type response. J. Immunol. 167, 442-450 (2001).

144 Montesano, M. A., Colley, D. G., Willard, M. T., Freeman, G. L. J. \& Secor, W. E. Idiotypes expressed early in experimental Schistosoma mansoni infections predict clinical outcomes of chronic disease. J. Exp. Med. 195, 1223-1228 (2002).

145 Steel, C., Guinea, A., McCarthy, J. S. \& Ottesen, E. A. Long term effect of prenatal exposure to maternal microfilaraemia on immune responsiveness to filarial antigens. Lancet $\mathbf{3 4 3}$, 890-893 (1994).

146 Saint-André, A. v. et al. The role of endosymbiotic Wolbachia bacteria in the pathogenesis of river blindness. Science $\mathbf{2 9 5}$ 1892-1895 (2002).

147 LoVerde, P. T. Do antioxidants play a role in schistosome host-parasite interactions. Parasitol. Today 14, 284-289 (1998)

Acknowledgements

We express our gratitude to J. Allen, A. Balic, N. Gomez, M. Taylor and $\mathrm{M}$. Wilson for discussions, criticism and permission to quote unpublished data. We thank A. van den Biggelaar and E. Sartono for immunoepidemiological data. We thank the Wellcome Trust and the Medical Research Council for funding, the European Union framework 5 and the Netherlands Organization for Scientific Research for support.

\section{(2) Online links}

\section{DATABASES}

The following terms in this article are linked online to:

LocusLink: http://www.ncbi.nIm.nih.gov/LocusLink/ CCL19 | CTLA4 | IFN- $\gamma$ | PGD 2 | PGE 2 | STAT6 | TGF- $\beta$ | TLR2 |

TNF

FURTHER INFORMATION

Rick Maizel's lab: http://helios.bto.ed.ac.uk/icapb/maizels/ Maria Yazdanbakhsh's http://www.lumc.n//1040/research/ immunology/immunology.html

Filarial genome network:

http://nema.cap.ed.ac.uk/fgn/filgen1.htm

http://www.nematodes.org/

Schistosome genome project:

http://www.nhm.ac.uk/hosted_sites/schisto/

Access to this interactive links box is free online. 